MST

PUELICATIONS

\section{PROPOSED DESIGN CRITERIA FOR SHALLOW BRIDGE FOUNDATIONS}

\section{Felix Y. Yokel}

U.S. DEPARTMENT OF COMMERCE National Institute of Standards and Tochnology Natlonal EngIneering Laboratory Center for Buliding Technology Galthersburg, MD 20899

Prepared for.

U.S. DEPARTMENT OF TRANSPORTATION Foderal Highway Administration Research, Development, and Technology Tumer-Fairbank HIghway Research Center 6300 Georgetown PIke

McLoan, VA 22101-2296

U.S. DEPARTMENT OF COMMERCE Robert A. Mosbacher, Secretary Leo Mercer, Deputy Under Secrotary for Technolosy

MATIONAL INSTITUTE OF STANDARDS

AND TECHNOLOGY

Raymond G. Kammer, Acting Director

100

.056

$90-4248$

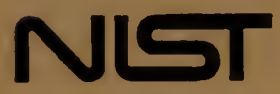

1990

C. 2 
NATIONAL INSTITUTE OF STANDARDS \&

TECHNOLOGY

Research Information Center

Grithersburn, MD 20399 


\section{PROPOSED DESIGN CRITERIA FOR SHALLOW BRIDGE FOUNDATIONS}

\section{Felix Y. Yokel}

U.S. DEPARTMENT OF COMMERCE Natlonal Institute of Standards and Tochnology

Natlonal EngInoering Laboratory Center for Bullding Technology

Galthersburg, MD 20899

\section{Prepared for:}

U.S. DEPARTMENT OF TRANSPORTATION Fodoral Highway Administration Research, Development, and Technology Turner-Fairbank HIghway Research Conter 6300 Georgetown PIke

McLean, VA 22101-2296

November

Issued February 1990

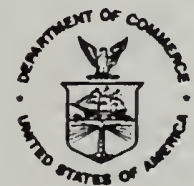

U.S. DEPARTMENT OF COMMERCE Robert A. Mosbacher, Secretary

Lee Mercer, Deputy Under Secretary for Technology

NATIONAL INSTITUTE OF STANDARDS AND TECHNOLOGY

Raymond G. Kammer, Acting Director 


\begin{abstract}
Criteria for the design of spread footings for highway bridges are proposed. The criteria address working load as well as load and resistance factor design (LRFD) procedures. Importance factors to be used in conjunction with the LRFD design format are proposed. The importance factors increase the design loads as the span length increases and also otherwise account for the severity of the consequences of a structural or foundation failure. Further data on LRFD design will be available from studies presently in progress. Available information on tolerances of highway bridges and other structures to foundation displacements are reviewed. On the basis of this information, allowable foundation-displacement limits are proposed. Unconditionally allowable foundation displacements will not affect the strength and serviceability of bridges and therefore do not require structural design modifications. These allowable displacements can be doubled if it either can be demonstrated, using criteria proposed in this report, that the strength and serviceability of the bridge is comparable to that required in accordance with applicable American Association of State Highway and Transportation Officials (AASHTO) specifications, or if the design of the bridge is modified so that the predicted foundation displacements can be accommodated.
\end{abstract}

Keywords: bridges; capacity reduction factors; cohesionless soils; design criteria; design limit states; foundations; foundation settlements; load factors; sands; soil; soil exploration; spread footings 
1. INTRODUCTION

2. PRESENT DESIGN PRACTICE

3. DESIGN LOADS

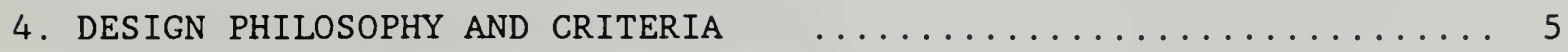

4.1 Performance Criteria (Required Reliability) ......... 5

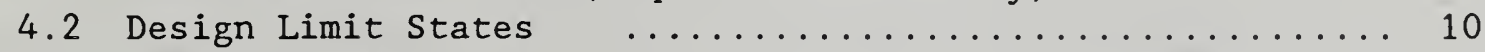

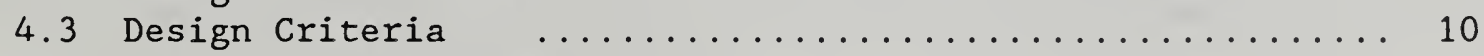

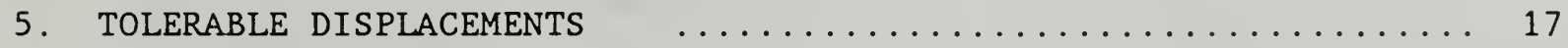

5.1 Parameters Affecting Tolerable Displacements _....... 17

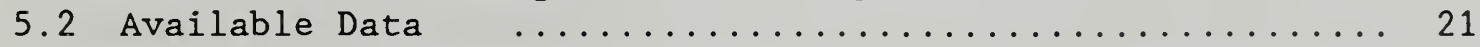

5.3 Design Limit States and Criteria $\ldots \ldots \ldots \ldots \ldots \ldots \ldots \ldots$

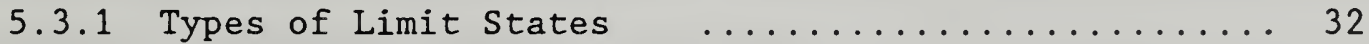

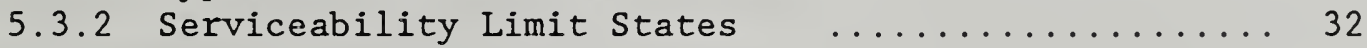

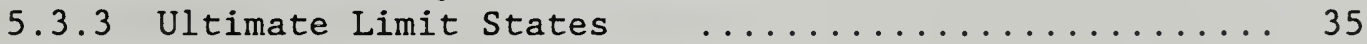

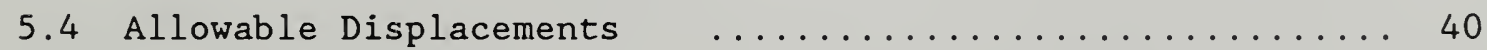

5.4 .1 Definitions $\ldots \ldots \ldots \ldots \ldots \ldots \ldots \ldots \ldots \ldots \ldots \ldots \ldots$

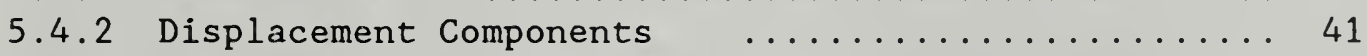

5.4 .3 Calculation of displacements $\ldots \ldots \ldots \ldots \ldots \ldots \ldots \ldots \ldots$

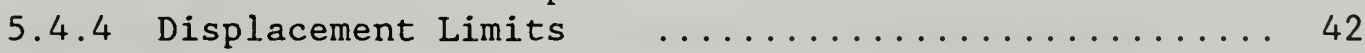

6. SUMMARY OF PROPOSED DESIGN CRITERIA $\ldots \ldots \ldots \ldots \ldots \ldots \ldots \ldots \ldots$

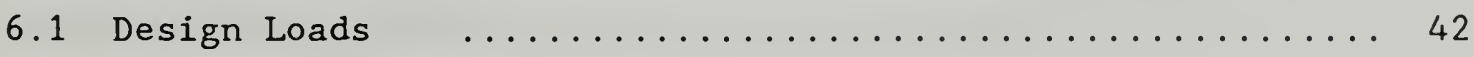

6.1 .1 Service Load Combinations $\ldots \ldots \ldots \ldots \ldots \ldots \ldots \ldots . \ldots \ldots$

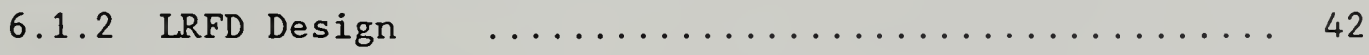

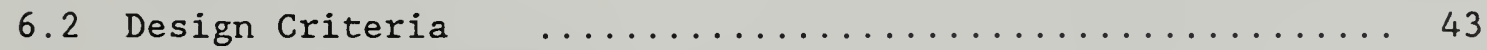

6.2 .1 Design Limit States $\ldots \ldots \ldots \ldots \ldots \ldots \ldots \ldots \ldots \ldots \ldots$

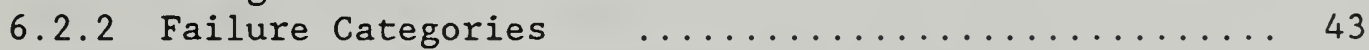

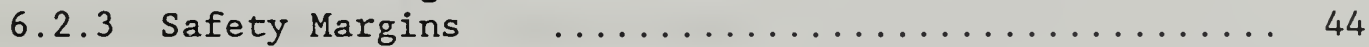

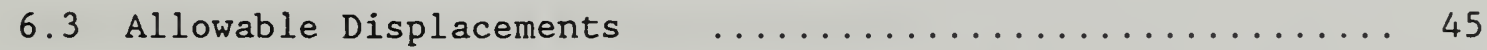

6.3.1 Unconditionally Allowable Displacements ........ 45

6.3.2 Conditionally allowable Displacements ........ 45

7. REFERENCES $\ldots \ldots \ldots \ldots \ldots \ldots \ldots \ldots \ldots \ldots \ldots \ldots \ldots \ldots \ldots$ 


\section{NOTATION}

$A=\delta / S($ or $\delta / \ell)=$ Angular distortion (radians)

$B=$ least width of footing ( $\mathrm{ft}$ or $\mathrm{m}$ )

$c=$ cohesion of soil (psf or $\mathrm{kPa}$ )

$\mathrm{D}=\operatorname{dead}$ load ( $1 \mathrm{~b}$ or $\mathrm{N}$ )

$\mathrm{D}_{\mathrm{p}}=$ dead load applied when and after bridge deck is poured ( $\mathrm{b}$ or $\mathrm{N}$ )

$D_{f}=$ depth of footing ( $f t$ or $m$ )

$\mathrm{E}=$ Modulus of elasticity (psi,or MPa)

F.O.S. = factor of safety (dimensionless)

$I=$ impact load ( $\mathrm{lb}$ or $\mathrm{N}$ ), also moment of inertia, (in ${ }^{4}$ or $\mathrm{mm}^{4}$ )

IF = importance factor (dimensionless)

$\mathrm{L}=$ live load ( $\mathrm{lb}$ or $\mathrm{N})$

$\ell=$ horizontal length ( $\mathrm{ft}$ or $\mathrm{m}$ )

$M_{e}^{\prime}=$ elastic moments due to service load + applicable portion of differential settlement at ultimate load ( $\mathrm{ft} \cdot \mathrm{lb}$ or $\mathrm{N} \cdot \mathrm{m}$ )

$\mathrm{M}_{\mathrm{p}^{+}}=$positive plastic moment $(\mathrm{ft} \cdot \mathrm{lb}$ or $\mathrm{N} \cdot \mathrm{m}$ )

$M_{p_{-}}=$negative plastic moment $(\mathrm{ft} \cdot \mathrm{lb}$ or $\mathrm{N} \cdot \mathrm{m}$ )

$\mathrm{N}_{\mathrm{c}}=\mathrm{f}(\phi)$ = bearing capacity factor for cohesion (dimensionless)

$\mathrm{N}_{\mathrm{q}}=\mathrm{f}(\phi)=$ Bearing capacity factor relating to $\mathrm{q}$ (dimensionless)

$\mathrm{N}_{\gamma}=\mathrm{f}(\phi)=$ Bearing capacity factor relating to $\boldsymbol{\gamma}$ (dimensionless)

$\mathrm{q}=\gamma \mathrm{D}_{\mathrm{f}}=$ overburden pressure at base of footing ( $\mathrm{psf}$ or $\mathrm{kPa}$ )

$q_{u}=$ ultimate bearing capacity of footing (psf or $k P a$ )

$\mathrm{S}=$ span length (ft or $\mathrm{m}$ )

$t=$ time (years)

$\beta=$ safety index (dimensionless)

$\gamma=$ unit weight of soil ( $\mathrm{lb} / \mathrm{ft}^{3}$ or $\mathrm{Mg} / \mathrm{m}^{3}$ )

$\gamma_{D}=$ load factor for dead load (dimensionless)

$\gamma_{L}=$ load factor for live load (dimensionless)

$\Delta=$ total settlement (in. or $\mathrm{mm}$ )

$\delta=$ differential settlement (in.or $\mathrm{mm}$ )

$\Phi=$ capacity reduction factor (dimensionless)

$\phi=$ angle of internal friction (degrees)

$\phi_{f}=\tan ^{-1}\left(\Phi_{\phi} \cdot \tan \phi\right)=$ factored value of $\phi$ (degrees)

$\Phi_{c}=$ capacity reduction factor for cohesive strength

$\Phi_{\phi}=$ capacity reduction factor for angle of internal friction 
$\therefore$

viii 


\section{INTRODUCTION}

1.1 Purpose and Scope of Report

When the foundation type for a highway bridge is selected, a decision has to be made whether to use deep foundations (piles or drilled shafts), or shallow foundations (spread footings). This decision is based on engineering judgment and economic considerations. In most instances pile foundations are more expensive than spread footings. A recent study [Gifford et al., 1987] indicates that for bridge-abutment and pier loads of less than 1,000 tons which are typical for highway overpass structures, the cost of pile foundations in 1986 dollars is on the order of $\$ 40$ to 80 per ton of pier load, depending on pile length, as compared with a spread footing cost on the order of $\$ 15$ per ton. For heavier foundations the cost of pile foundations is on the order of two to three times that of spread footings. These cost differentials can only be justified if the increase in initial construction cost is offset by a corresponding decrease in maintenance and replacement cost and anticipated costs resulting from structural failures.

In many instances, such as in cases where scour could occur, where thick layers of soft soil are present, or where long-term consolidation settlements are anticipated, deep foundations are an obvious and undisputed choice. However in other instances, particularly when the foundations rest on granular soil, the choice of deep foundations is often based on tradition, lack of knowledge about tolerable settlements which leads to unreasonably restrictive requirements, and uncertainty about the magnitude of anticipated settlements. In these latter instances, the choice seems to be dictated by conservatism resulting from the lack of experimental data and the lack of confidence in the ability to predict performance, rather than by sound economic considerations.

The purpose of this report is to provide information which will help engineers to determine tolerable settlements for bridge foundations. This information, in turn, is designed to remove one of the obstacles to the choice of spread footings for highway bridge foundations. 
The design of deep foundations tends to be dictated by load capacity considerations, since settlements are usually assumed to be within tolerable limits. On the other hand, the design of spread footings, because of their geometry, the range of applicable soil conditions, and the range of allowable settlements presently under considexation, is predicated primarily on settlement control and not on bearing capacity failure, which seldom, if ever, governs. For this reason, the primary emphasis in this report is on settlements.

Over the last decade, the Federal Highway Administration has sponsored extensive research in two critical areas associated with the design of shallow bridge foundations: The tolerance of highway bridges to settlement, which is summarized by DiMillio 1982, Moulton et al., 1985, and Moulton, 1986; and the prediction of settlements on the basis of site exploration data, which is reported by Briaud, 1986, and Gifford et al., 1987. Since the publication of the report by Gifford et al., further work has been performed on some of the settlement data points in the Gifford et al. report, which further corroborated the validity of the data points examined. The data on the tolerance of highway bridges to foundation displacements available from the research reports previously referenced, as well as other information in the literature, form the basis for the design criteria proposed in this report.

The most important conclusion of this study, which differs from recommendations presented in previous studies, is that in granular soils most bridge types can be supported by spread footings, designed by presently accepted criteria for building foundations, without modifying the design of the superstructure to accomodate differential settlements.

Present design practice is discussed in Chapter 2. Design loads are recommended in Chapter 3. Chapter 4 deals with safety margins and load and resistance factors. Tolerable displacements are discussed in Chapter 5. The proposed design criteria are summarized in Chapter 6. Unless specifically noted otherwise, the design methods and procedures proposed in this report comply with the provisions of the 1983 AASHTO specifications or their 1984, 1985, 1986, and 1987-8 supplements. 


\section{PRESENT DESIGN PRACTICE}

Present AASHTO "Standard Specifications for Highway Bridges" 1983, and their referenced supplements [3] do not explicitly limit allowable foundation settlements. In Division II, Section 3.6.3.1 of the document it is stated for pile load tests that: "The safe allowable load shall be considered as $50 \%$ of that load which, after a continuous application of 48 hours, produces a permanent settlement not greater than $1 / 4$ inch $(6 \mathrm{~mm})$ measured at the top of the pile. This maximum settlement shall not be increased by a continuous application of the test load for a period of 60 hours or longer." Since "permanent settlement" is interpreted to imply a residual settlement after the test load is removed, this clause also neither defines nor limits the allowable settlement. Moulton, 1986 concluded that: " in general, the design practices of those States surveyed (in conjunction with the cited report) do not consider any tolerable movement criteria in the design of their bridges". In view of this information it is difficult to make any generalizations about the settlements associated with present design practice.

For the design of shallow foundations, the present AASHTO specifications (19871988) refer to Peck et al., 1974. Implicit in the recommendations for foundation design for granular soils included in that latter reference is a limit of 1 inch (25 mm) for total settlements and $3 / 4$ inch (19 mm) for differential settlements.

The AASHTO specifications also do not explicitly specify safety margins against overall bearing capacity failures, which would rarely govern the design of spread footings. However, reference is made to the design procedures recommended by Peck et al., 1974, which recommend global safety factors of 3 for the design of spread footings in cohesive soils, and incorporate a safety factor of 2 against bearing capacity failures in their design charts for spread footings on sands. It is, however, important to recognize that the conservatism inherent in the design procedures for cohesionless soils (sands and silts) actually recommended by Peck et al. is likely to result in settlements significantly smaller than 1 inch $(25 \mathrm{~mm})$ and in safety factors significantly larger than 2 against stability and bearing capacity failures. 
In current U.S. practice the Standard Penetration Test (ASTM D 1586), the quasistatic cone penetration test (ASTM D 3441), and occasionally the Pressuremeter test (ASTM D 4719) are used to determine the in situ properties of cohesionless soils. Laboratory tests are less effective because it is difficult to retrieve undisturbed samples. Design procedures for industrial or residential buildings generally tend to be based on settlement limitations on the order of 1 inch (25 $\mathrm{mm}$ ); however, in some instances more severe limitations are used [Canadian Foundation Engineering Manual, 1978].

\section{DESIGN LOADS}

The AASHTO specifications (AASHTO, 1983) state in Article 3.22.3 that load factors are not to be used in the design of foundations, or in checking for foundation stability. However, some studies of load and resistance factor design (LRFD) for bridge foundations were conducted in the past [Snyder and Moses, 1978] and additional studies are now in progress. Therefore, LRFD design is considered in this report. The limit-state design philosophy inherent in LRFD design also is used to demonstrate that bridges can accomodate foundation settlements of certain magnitudes without impairment of their serviceability and load capacity.

Design loads recommended are either design service loads or factored loads to be used with LRFD design. In either case, the loads, as well as the load factors are those specified in AASHTO, 1987, table 3.22.1. A (even though, in accordance with present AASHTO Specifications, these factors are not applicable to foundation design). In accordance with Article 3.8 in AASHTO, 1983, impact load is not included in the live load recommended for foundation design.

The following load combinations are relevant for shallow foundation design:

(1) Service Load Combinations:

The most critical load combination applicable to foundation design, as specified in AASHTO, 1983, table 3.22.1.A and subsequently amended should be used. Group I 
loading is relevant for all areas, and Group VII loading must be satisfied wherever applicable in accordance with the seismic risk map in figure 3.21.1.E.

(2) LRFD Design:

The most critical load combination applicable to foundation design, as specified by AASHTO, 1983, table 3.22.1.A and subsequently amended should be used. Because, in the Group I loading, the load factor specified for dead load is 1.3 and that for live load is 2.17 or more, the design load decreases as the dead load becomes larger compared to the live load. It is therefore recommended that the design gravity load not be smaller than 1.5 (Dead + Live), which is the factored Group I load for a $200-\mathrm{ft}(60-\mathrm{m})$ long span. This latter recommendation is in agreement with the AASHTO "Guide Specification for Strength Design for Truss Bridges", 1985. As in the case of service load combinations, Group I and VII loadings are applicable in most instances.

When the design of the superstructure is modified because anticipated differential settlements are deemed to affect the load capacity of bridges, the magnitude of the settlement effects for which the design is modified should correspond to the level of the loads used to design the superstructure.

\section{DESIGN PHILOSOPHY AND CRITERIA}

\subsection{Performance Criteria (Required Reliability)}

The required reliability against failure or unsatisfactory performance can be stated in the form of performance criteria. Since the ultimate purpose of the foundation is to support the superstructure, it is reasonable to state the performance criteria for the foundation as well as the superstructure, and then identify design limit states for the foundation which would violate these performance criteria. Ideally, the criteria should be stated in terms of required reliability against various types of failure, distress or malfunction. However, in absence of a valid and accepted methodology by which these levels can be quantified, the criteria can also be stated in terms of required 
traditional (global) safety factors or load and resistance factors. The following failure categories are proposed:

I: Catastrophic failure - a failure associated with major loss of life and property, or the protracted disruption of traffic in a major artery. An example of a catastrophic failure would be a foundation failure wh $i c h$ would collapse a bridge span in a major artery.

II: Major structural failure - a foundation failure which renders all or a major part of the bridge structure or its foundation unserviceable until a major structural component is replaced. An example would be a flexural or shear failure in a bridge girder as a result of excessive settlements.

111: Structural distress - A failure which requires repair work or which is esthetically unacceptable or impairs durability, but does not render the bridge unserviceable. An example would be an unacceptable level of cracking in the deck.

IV : Functional failure - a failure which temporarily or permanently causes the bridge or its approaches to improperly fulfill their function (for instance drainage or riding quality problems caused by settlements).

Some information on reliability levels has been compiled from data and studies on existing structures from which failure probabilities can be deduced. A summary of such data is shown in figure 4.1 which was taken from Whitman, 1984. In accordance with these data the risk of foundation failures would generally range from an annual probability of $10^{-2}$ to $10^{-3}$. These high failure probabilities are unacceptable for highway bridges when one considers the number of bridges in use, as well as the fact that the public in this case is exposed to an involuntary risk. One should keep in mind that most of the failures which served as a basis for figure 4.1 were the result of either outright design or construction errors, or conditions which were not anticipated by the designers. Very few of these failures are attributable to occurrence of any of the limit states assumed by the designers. Consequently, these high failure 


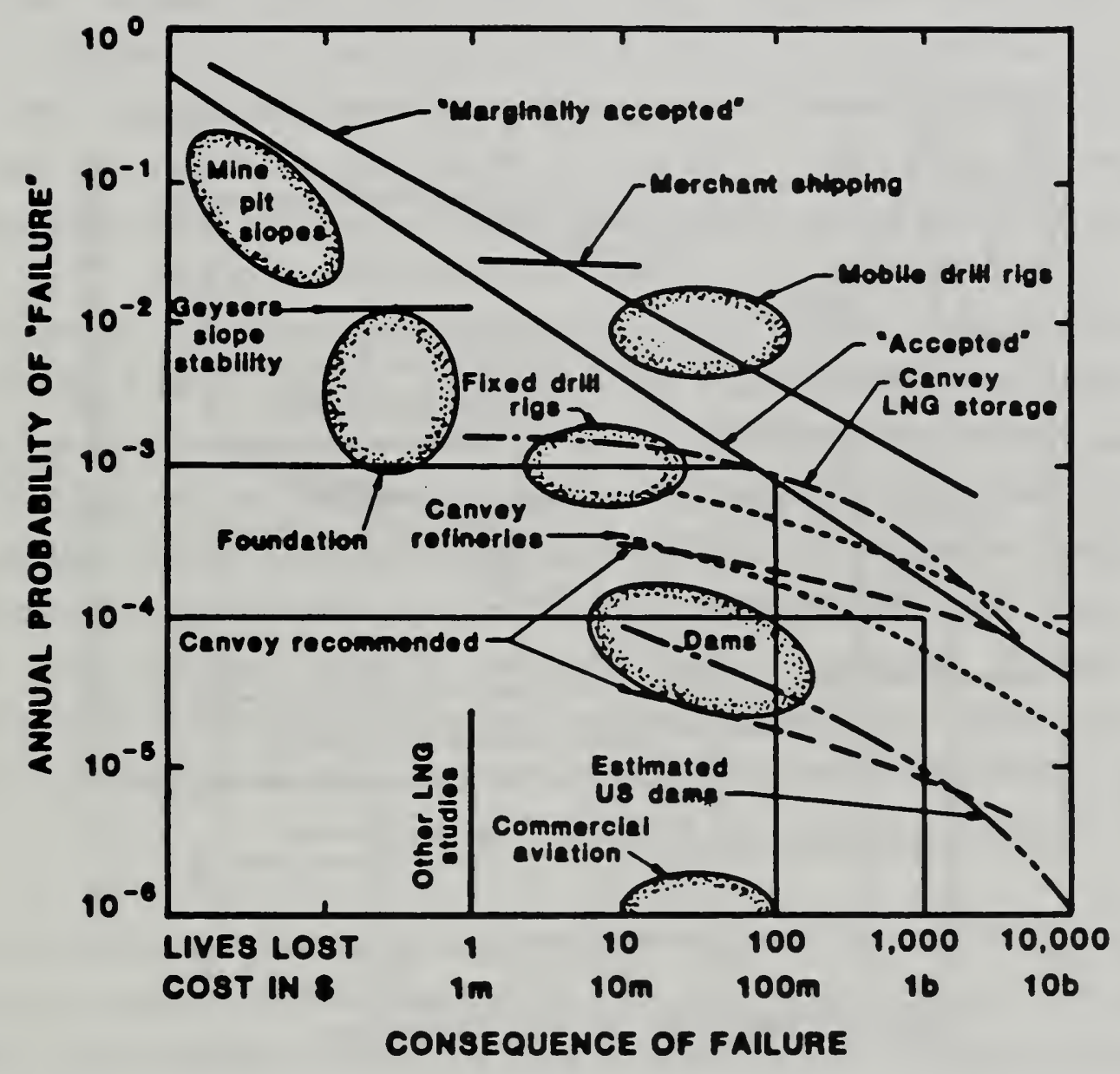

Figure 4.1: Risk for Selected Engineering Projects (taken from Whitman, 1984) 
probabilities can best be reduced by enhancing the quality of the subsurface investigation and construction supervision.

More specific guidance can be derived from recently developed standards for load and resistance factor design (LRFD). The most recently developed document is the first edition of the American Institute of Steel Construction (AISC) Manual [AISC, 1986]. This latter document is calibrated to reliability indices ranging from 2.5 to slightly over 3.5 with respect to a failure during the service life of the structure. The rationale for these indices, which mainly rests on the calibration of existing design practice, is discussed by Galambos et al., 1982, and Ellingwood et al., 1982. "Reliability indices" were defined by Galambos et al., 1982, and can be viewed as a measure of the failure probability in terms of the combined variabilities of the load and resistance.

These indices imply notional failure probabilities during the service life of the structure, which was assumed to be 50 years, ranging from 0.0002 to 0.006 . While these "notional" probabilities are defined in terms of the mathematical models which use a limited number of parameters and do not necessarily reflect actual failure probabilities in the field, the calculated safety indices provide a useful tool for comparing various structural systems and calibrating the required safety margins. Until further studies provide more detailed information, target reliability indices for a 50 or 100-year reference period (depending on the design service life) of 3.5 or more for category I failures, and 2.5 or more for category II failures are suggested.

For category III and IV failures appropriate failure probabilities could be determined by a cost-benefit analysis as illustrated by figure 4.2, which is taken from Dunn, 1985. The essence of such an analysis would be that a decrease in the allowable foundation pressure and thus the anticipated settlement is justified up to the point where the cost of an increment of decrease in the estimated average settlement is about equal to the savings in maintenance and repair costs resulting from this incremental decrease. Such an analysis could be useful in calibrating safety margins in design provisions. In practice, however, it may be difficult to generate the required data for a single design. 


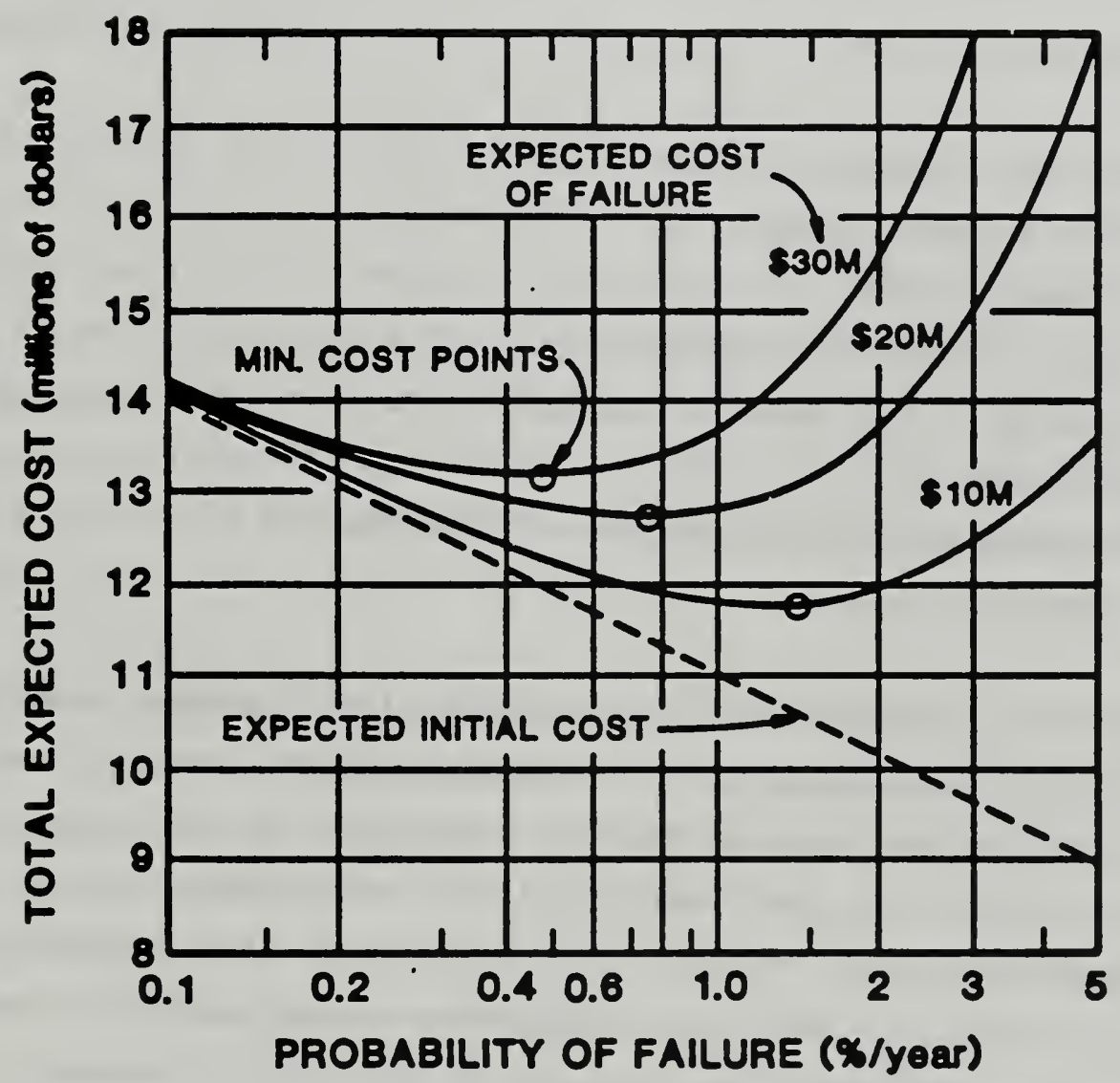

Figure 4.2: Application of Reliability Analysis in Cost Optimization (taken from Dunn, 1985) 
Thus, until further studies are conducted, it is suggested to use a reliability index of 1.3 or more for a 50 or 100 year reference period.

The preceding discussion presupposes that it is possible to determine variabilities of predicted soil strength and stiffness and of other parameters which could contribute to the uncertainty of predicting actual performance. While ordinarily in engineering design these variabilities are not quantified, methodologies for such quantification have been suggested [Gifford et al., 1987, Baecher, 1987 [Reports 87/010 and 87/011)].

\subsection{Design Limit States}

Five design limit states are identified:

1. Bearing capacity failure

2. Rotational sliding

3. Sliding at the base of the footing

4. Settlements which cause structural failure or impair the load capacity of the structure

5. Settlements which cause structural distress or functional failure.

The first three limit states are ultimate limit states related to the shear strength of the supporting soil. The fourth limit state is an ultimate limit state related to the compressibility (stiffness) of the supporting soil. The fifth limit state is a serviceability limit state related to the compressibility of the supporting soil. The ultimate limit states are related to category I or II failures and thus should have appropriate safety margins. The serviceability limit state should ideally be evaluated on the basis of economic considerations.

\subsection{Design Criteria}

Three levels of sophistication can be used in the design: (1) a probabilistic approach; (2) an LRFD approach; and (3) a working load design approach, using global safety factors. In the first two approaches the variability of the estimated strength and stiffness parameters must be accounted for in the design 
procedure. It will be seen from the discussion below that if strength reduction factors in the LRFD approach are determined on the basis of soil properties alone, the resulting design will not be identical with the working load design, unless adjustments are made for the length of the bridge span.

The proposed LRFD and working load design approaches are predicated on the assumption that load capacities and settlements will be calculated by methods which are not less conservative than traditional geotechnical engineering practice.

1. The probabilistic approach.

This approach can only be used when soil exploration data of sufficient quantity and quality are provided. An adequate justification must be provided for the safety margins used. Target safety indices over a 50 or 100-year reference period of not less than 3.5 and 2.5 are suggested for Category $I$ and II failures, respectively. A safety index of not less than 1.3 (a 10\% probability that settlements will be exceeded during the service life) is suggested against the settlement threshold for structural distress, unless a lower safety index can be justified by a cost-benefit analysis.

Since probabilistic approaches require sophisticated methods of analysis, they are not further discussed in this report. If a probabilistic approach is used, the variability of the soil resistance must be fully documented by the engineer on the basis of soil exploration and laboratory test data. It is also noted, that the variability of the design loads, as well as that of the soil resistance parameters must be taken into consideration.

\section{The Load and Resistance Factor Design (LRFD) approach}

LRFD design will be increasingly used in the future. In this design approach a safety margin is provided by combining a factored load with a factored resistance. Load factors are generally larger than 1 and are designed to account for the variability of the load. Resistance factors are smaller than 1 and account for the variability of the resistance. In each instance the average 
load factor divided by the resistance (capacity reduction) factor is equivalent to the safety factor used in working load design. However, the LRFD approach is intended to better account for load and strength variability than the working load design approach, and thus could enhance safety and economy. Another incentive for introducing LRFD design for foundations is the fact that factored loads are already used to design the superstructure and it would be convenient to use the same loads for foundation design.

Factored loads to be used with this approach were defined in Section 3 . Studies of options for capacity reduction factors for bridge foundations are now in progress.

It was previously noted that the LRFD approach and the working load approach will not yield identical results if capacity reduction factors are based on the variability of the soil strength parameters alone. The discrepancy results from the fact that, for instance in Group I loading, the load factor for the dead load is 1.3 and that for the live load is $1.3 \times 1.67=2.17$. The effect of this difference between the load factors for dead and live loads on bridge foundation design is subsequently examined.

The ratio of dead to live load increases with increasing span length and has been estimated by the following equation [Hansell and Viest, 1971]:

$$
\frac{D}{\mathrm{~L}+\mathrm{I}}=0.0132 \cdot \mathrm{S} \quad \ldots \text { (4.1) }
$$

where: $D=$ dead load

$\mathrm{L}=$ live load

$I=$ impact load

$\mathrm{S}=$ span length in feet.

Since impact load is not used in foundation design, it must be eliminated from the equation. Using the AASHTO equation for impact load:

$$
I=\frac{50 \cdot L}{S+125} \leq 0.30
$$

the following expression for the Ratio $\frac{D}{L}$ was derived [Schneider et al., 1978]:

$$
\frac{\mathrm{D}}{\mathrm{L}}=\left(1+\frac{50}{\mathrm{~S}+125}\right) \cdot 0.0132 \cdot \mathrm{S} \quad \ldots(4.2)
$$

The inequality that must be satisfied in LRFD design is: 


$$
\Phi R \geq \gamma_{D} D+\gamma_{L} L
$$

where: $\gamma_{D}$ and $\gamma_{L}=$ the load factors for dead and live load

$\Phi=$ the capacity reduction factor for resistance

The minimum global safety factor calculated from this inequality is:

$$
\text { F.0.S }=\frac{\gamma_{D} D+\gamma_{L} L}{\Phi(D+L)}
$$

Equations 4.2 and 4.4 can be used to calculate global safety factors for foundations for bridges of various span lengths. Figure 4.3 shows a plot of global safety factors versus span length, assuming an overall capacity reduction factor of 0.6 , and load factors of 1.3 for dead load and 2.17 for live load, which are in accordance with present AASHTO specifications.

It can be seen from the figure that the global safety factor for the 30-ft (9-m) span is 3.12 and that for the $200-\mathrm{ft}(61-\mathrm{m})$ span is approximately 2.52 (the minimum design load of $1.5(D+L)$ specified in the AASHTO strength design specifications for truss bridges would yield a global safety factor of 2.5). Thus, if LRFD load factors are used, the global safety factor for the $30 \mathrm{ft}$ span would be 248 higher than that for the $200 \mathrm{ft}$ span. On the other hand, foundations designed in accordance with present practice will tend to have similar global safety factors for the $30 \mathrm{ft}$ and the $200 \mathrm{ft}$ spans (or perhaps the foundation for the $200 \mathrm{ft}$ span would be designed more conservatively by some engineers, accounting for the consequences of a potential failure). Thus, if future LRFD design is to be calibrated to provide safety margins similar to those used in present practice there would have to be some correction factor for span length. To accomplish this correction, an "importance factor" is suggested in this report to also account for the consequences of failures. This factor also enables us to distinguish between Category I and Category II failures.

The following modified design equation is suggested:

$$
\Phi R \geq \operatorname{IF}\left(\gamma_{D} D+\gamma_{L} L\right)
$$

where: $\quad I F=$ Importance Factor 


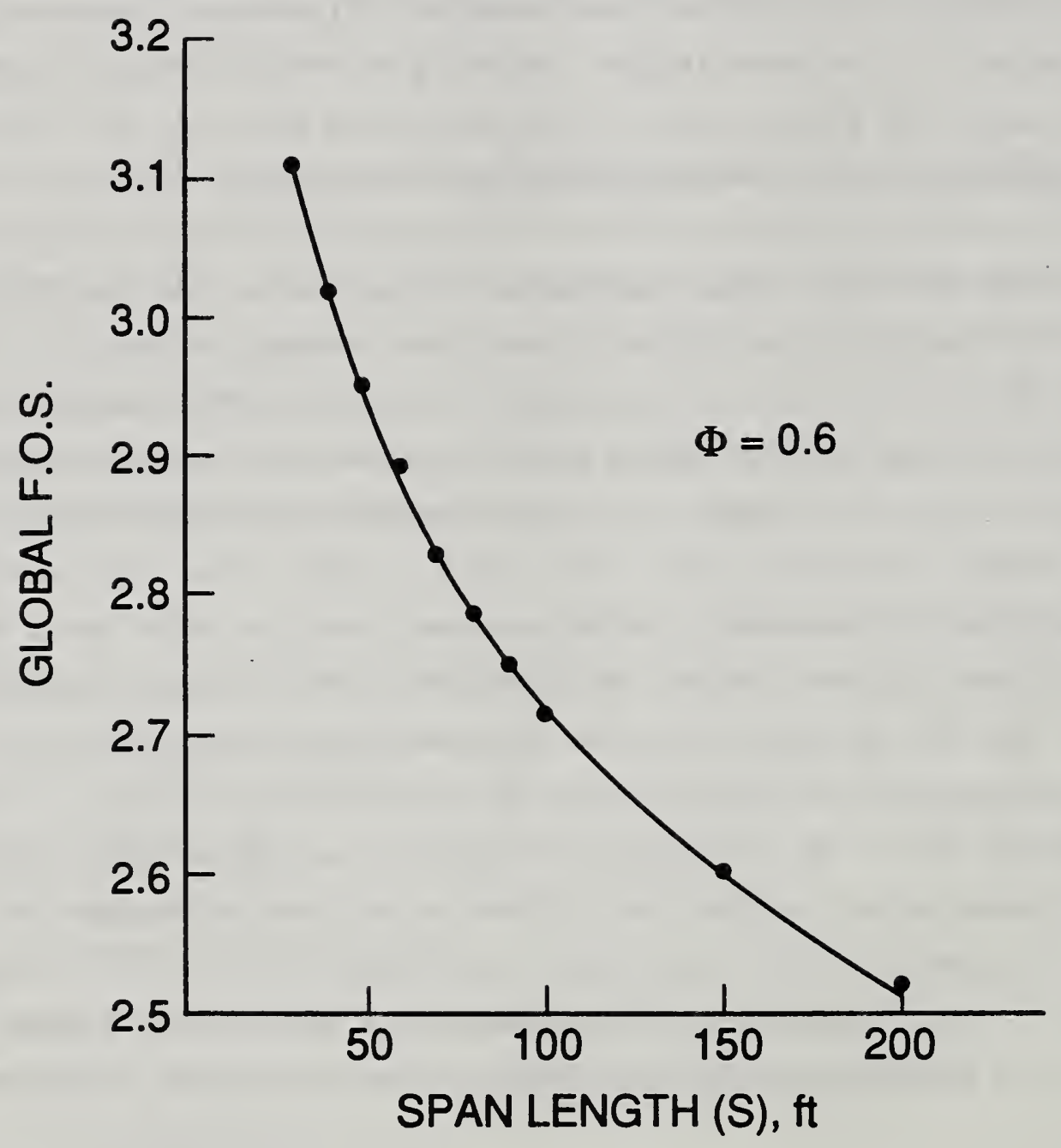

Figure 4.3 Correlation Between Span Length and Global Safety Factors Resulting from LRFD Design. 
If no correction for span length effects is desired:

$$
\begin{array}{ll}
I F=1.2 & \text { for Category I failures } \\
I F=1.0 & \text { for Category II failures. }
\end{array}
$$

If a correction for span length effects is included:

$$
\begin{aligned}
& \mathrm{IF}=0.54 \cdot \mathrm{S}^{0.2} \text { for Category I failures } \\
& \mathrm{IF}=0.45 \cdot \mathrm{S}^{0.2} \text { for Category II failures } \ldots(4.7)
\end{aligned}
$$

For a $\Phi$ (capacity reduction) factor of 0.6 , and Group I loading, the importance factors in eq.4.7 would produce global safety factors of 2.77 and 3.28 , respectively, for a 30-ft and a 200-ft span for Category II failures, and global safety factors of 3.32 and 3.93, respectively for a 30 -ft and a 200 -ft span for Category I failures. Equation 4.6 would merely distinguish between Category I and Category II failures and result in a decrease in the global safety factor as the span increases.

Resistance factors for spread footings are now under study. One possible approach, proposed by Snyder and Moses, 1978, is discussed hereafter. However, a different approach is likely to be ultimately adopted after completion of the present studies.

Snyder and Moses derived resistance factors by calibrating existing design practice, using Terzaghi's bearing capacity equation [Terzaghi, 1956]:

$$
\mathrm{q}_{\mathrm{u}}=\mathrm{cN}_{\mathrm{c}}+\frac{1}{2} \gamma \mathrm{BN}_{\gamma}+\mathrm{qN}_{\mathrm{q}}
$$

where: $\mathrm{q}_{\mathrm{u}}=$ ultimate bearing capacity of footing

$\mathrm{c}=$ cohesion of soil

$\mathrm{N}_{\mathrm{c}}=\mathrm{f}(\phi)$ = bearing capacity factor for cohesion

$\phi=$ angle of internal friction

$\gamma=$ unit weight of soil

$B$ = least width of footing

$\mathrm{N}_{\gamma}=f(\phi)$ = bearing capacity factor relating to $\gamma$

$\mathrm{q}=\gamma \mathrm{D}_{\mathrm{f}}=$ overburden pressure at base of footing

$\mathrm{D}_{\mathrm{f}}=$ depth of footing

$\mathrm{N}_{\mathrm{q}}=\mathrm{f}(\phi)$ = bearing capacity factor relating to $\mathrm{q}$

Using this equation, a global safety factor of 3 for typical design situations, and a conservative approach with respect to the choice of $D / L$ ratios, Snyder and Moses came up with the following recommendation:

$$
\Phi_{\mathrm{c}}=0.5 ; \quad \Phi_{\phi}=0.8 \text {, where } \phi_{\mathrm{f}}=\tan ^{-1}\left(\Phi_{\phi} \cdot \tan \phi\right)
$$


where: $\Phi_{c}=$ reduction factor for cohesive strength

$\Phi_{\phi}=$ reduction factor for angle of internal friction

$\phi_{f}=$ factored value of $\phi$ from which the reduced values of bearing capacity factors are calculated.

The above recommendations are considered by their authors to be applicable to all types of foundations, including retaining walls and piles. Without the use of an importance factor similar to that proposed in Eq 4.7 these recommendations would result in an increase of the safety factor with decreasing bridge spans of the order shown in figure 4.3. Whether such an increase is justified is a matter of philosophy which should be resolved by professional consensus. On the one hand, the relative increase in live load, which is less predictable than the dead load, would justify an increase in the safety factor. On the other hand, the severity of the consequences of failure in potential loss of life and property increases as the bridge span increases. Another issue which needs consideration is the global safety factor used by Snyder and Moses when calibrating the load factors. The safety factor of 3 is consistent with present practice for footings in clay. For sands a factor of 2 is suggested by Peck et al.,1973, but their determination of $\phi$ from penetration tests is very conservative.

For the serviceability limit state it is proposed to use unfactored loads and settlements. This proposed approach is based on the assumption that the geotechnical engineer will calculated settlements deterministically, and arrive at an estimated conservative upper bound rather than an estimated mean settlement. Should a more sophisticated approach be used, where the mean and standard deviation are estimated, the design settlement should not be less than the predicted mean settlement +1.3 standard deviations.

\section{The working-load design approach}

The global safety factor against Limit States 1, 2 and 3 should be not less than 3.6 for Category I failures and 3 for Category II failures. Limit State 4, if applicable, must be evaluated by the LRFD method (it is not applicable when the unconditionally allowable displacements are not exceeded). Limit State 5 should be evaluated in the same way as proposed for the LRFD approach. 


\section{TOLERABLE DISPLACEMENTS}

\subsection{Parameters Affecting Tolerable Displacements}

Displacements that result from the loads acting on foundation elements are predominantly vertical downward translations, and rotations of foundation elements. In some instances horizontal translations of foundation elements and vertical uplift may also occur. Normally spread footings are designed for allowable bearing pressures, chosen for each foundation element in accordance with the soil conditions, as determined by in-situ or laboratory tests. The result of these design procedures will be to approximately equalize the vertical downward displacements of the different foundation elements that support the structure. However, many of the procedures used may result in some differential settlements, particularly when the foundation elements differ in size. These theoretical differential settlements can be estimated or avoided by specifically designing all foundation elements for the same predicted settlement. However, because of variability in the soil and loading conditions there will be differential settlements even if the designer takes care to avoid such settlements. The differential settlements, which for the most part are settlements over which the designer has no control, have been estimated to be on the order of $75 \%$ or less of the estimated total settlement in granular soils [Peck et al., 1973].

It should be noted that differential settlements also occur in many pile foundations designed in accordance with present practice. Thus, unless the foundations are supported by rock or very short end bearing piles or otherwise specifically designed to equalize settlements, a condition which is neither explicitly specified in present standards nor implicit in present design procedures, it is reasonable to assume that most bridges, whether simple span or continuous, experience differential settlements for which no allowance was made in the design. These differential settlements rarely cause distress.

The structural elements of bridges are not sensitive to settlements which result in a rigid-body downward displacement (uniform settlements) or rigid-body rotation of the entire structure. However they are sensitive to differential 
settlements between foundation elements and to horizontal displacements which change the horizontal distance between supports or result in misalignment of supports. This does not imply that large uniform settlements are tolerable if they are not accompanied by differential settlements which can damage the structure. Large uniform settlements can cause alignment and drainage problems and could affect riding quality. Thus, total as well as differential settlements must be limited.

Differential settlements induce bending moments and shear in girders when spans are continuous over supports and can lead to structural damage or failure. To a lesser extent, they can also cause structural damage to the deck of simple span bridges. However, settlement-induced discontinuities in the slope of the riding surface at the supports of simple span bridges may be more severe than those in continuous spans. Such discontinuities can affect the riding quality of the pavement. It has been determined in a number of studies [i.e. Grant et al., 1972, and 1974, Skempton and McDonald, 1956] that the severity of the differential settlement effect on structures is roughly proportional to the "angular distortion", (A), a term that has been defined as the differential settlement between two adjacent foundation elements divided by the distance between these elements (sometimes corrections are made for rigid-body rotation). For bridges, the "longitudinal angular distortion" is herein defined as the differential settlement divided by the span length. It is a dimensionless quantity expressed as an angle in radians. Implicit in this definition is the assumption, based on available data which will be discussed in the following section, that the severity of differential-settlement effects is directly proportional to the differential settlement and inversely proportional to the span length.

Horizontal displacements mostly occur at abutments and at pier footings adjacent to approach fills. In most instances the horizontal displacements are caused by approach pavement growth or are associated with approach embankment fills, which cause rotations and translations of abutments and footings. In some instances, particularly in the case of abutments supported by piles, footing rotations induced by approach embankment fills result in horizontal displacements toward the embankment. Horizontal displacements can cause damage to bearings and 
abutments, especially to backwalls, and reduce the effectiveness of, or completely jam, expansion joints. Jamming of expansion joints in turn can result in severe structural damage or failure. Available data indicate that the effect of horizontal displacements is independent of the length of the adjacent bridge span.

Another important parameter is the time over which the settlement occurs. In fine grained soils with low permeability the settlement may occur gradually over a long period of time. Thus, most of the settlement will occur after the construction is completed, and short term peaks in the live load will have little effect on the total settlement. In granular soils, most of the settlement occurs within a short time after the load is applied (during construction). Thus the sequence of load application during construction will influence the effect of the settlement on the structure and the overall settlement effect in granular soils will be significantly less than that in fine grained soils. On the other hand, short time peaks in the live load must be taken into account when determining settlement effects in granular soils. Since this report deals with granular soils, settlements are assumed to occur within a short time after load application and short term peaks in live load (but not impact) are taken into consideration.

The difference between simple spans and continuous girders and long and short spans was already noted. While there is considerable empirical evidence that angular distortion is a relevant parameter when correlating differential settlements with many types of damage, a more complex analysis is necessary when it is desired to determine the actual stress increase induced in girders or decks by differential settlements. The relevance of the angular distortion parameter can be shown qualitatively. The moment induced in a bridge girder by the settlement of one of the supports is a function of the length and stiffness of the girder:

$$
\begin{aligned}
& M \propto \frac{3 E I \delta}{\ell^{2}} \text { if the girder is simply supported on one } \\
& \ell^{2} \quad \text { support and continuous (fixed) on the other support, } \\
& M \propto \frac{6 E I \delta}{\ell^{2}} \text { if the girder is fixed at both ends } \ldots(5.1)
\end{aligned}
$$


Thus $M=f\left(\frac{E I \delta}{\ell^{2}}\right)=f\left(\frac{E I A}{l}\right)$, since $A=\frac{\delta}{\ell}$

where: $\quad E=$ modulus of elasticity

$I=$ moment of inertia of girder section

$\mathrm{A}=$ angular distortion

$\ell=$ length of girder

$\delta=$ differential settlement

The stress increase caused by the induced moment would be a function of EdA/ $\ell$, where $d$ is the depth of the section. If $E d / \ell$ is assumed to be relatively constant because of other design constraints, then the angular distortion is indeed a reasonably good measure of structural effects of differential settlements. This aspect of the problem has been a subject of a recent FHWA study [Moulton et al., 1985, Moulton, 1986] and is discussed in the following section. Note also that for the same settlement and span the settlement-induced moment in a two-span continuous bridge will be $1 / 2$ of that in an interior span of a multi-span continuous bridge.

The sequence of construction is also important. For instance, if a prestressed or post-tensioned concrete structure is made continuous for live load by cast in place joints, the only settlements which will affect the superstructure are the settlements which occur after tensioning (this applies only to granular soils where long-term settlements are small), i.e. the live load settlements, which in many instances would be less than $1 / 4$ of the total settlements. Proper construction sequencing can also prevent most of the horizontal displacements at abutments and near embankment fills, which tend to be very problematic in terms of structural damage.

For reinforced concrete bridges, creep relaxes the stresses induced by differential settlements. In the case of granular soils, the maximum differential settlement effects occur a short time after completion of construction. Subsequently the induced stresses decrease substantially because of creep effects. Thus, the chances that maximum live loads occurrence would coincide with maximum differential settlement effects are very small. 


\subsection{Available Data}

Most studies related to tolerable foundation settlements were for buildings rather than bridges. Grant et al., 1972 and 1974, and Skempton and MacDonald, 1956, analyzed case histories where field observations of building distress and differential settlement measurements were available and attempted to determine settlement thresholds above which objectionable structural or architectural damage occurs.

An approximate threshold value for building distress emerging from these studies is an angular distortion of $1 / 300$. It should be noted that Grant et al. corrected angular distortions by subtracting rigid-body rotation. A similar procedure was not used by Skempton and McDonald and in the FHWA reports discussed later in this section. The net effect of this difference is that angular distortions which are not corrected for rigid-body rotations are in some instances larger than the corrected distortions.

A very important aspect of the data by Grant et al. and Skempton and McDonald is that they indirectly (via the distortion parameter) establish correlations between maximum (measured) total settlements, maximum differential settlements and maximum angular distortions for the documented sites for granular soils, as well as clays. The correlation for isolated footings on granular soils, taken from Grant et al., 1972, is shown in figure 5.1. A somewhat different correlation was developed for mat foundations which are outside the scope of this report. The correlation in fig. 5.1 was found not to be very sensitive to the type or size of the structure. The consistency of the data indicates that, at least as far as empirical evidence can be interpreted, total settlements, differential settlements and angular distortions are not necessarily independent variables. The correlations developed for sands are:

$$
A \simeq \Delta / 600 \simeq \delta / 360, \quad \ldots(5.3)
$$

where: $\Delta$ and $\delta$ are the maximum total, and the maximum differential settlement, respectively. 


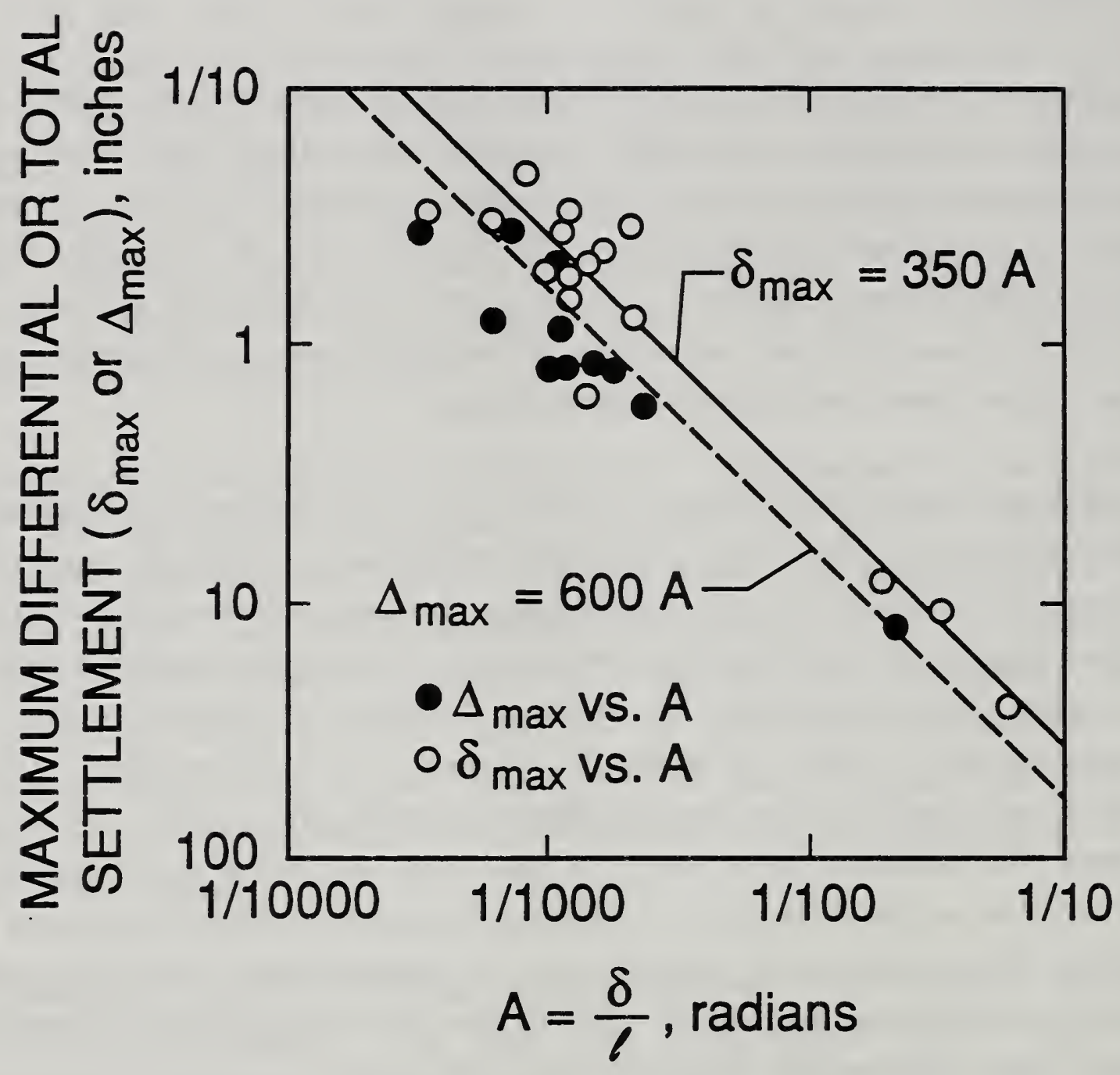

Figure 5.1: Correlations Between Total Settlements, Differential Settlements and Angular Distortions in Granular Soils (after Grant et al. , 1974). 
This correlation also leads to the conclusion that:

$\delta \simeq 0.6 \Delta$ and threshold values for $\Delta$ and $\delta$ are 2 inches $(50 \mathrm{~mm})$ and 1.2 inches $(30 \mathrm{~mm})$, respectively.

Another significant finding of the studies reported by Grant et al. is that, while a maximum angular distortion of 1/300 for any particular building site was usually associated with unacceptable damage, the damage did not necessarily occur in the vicinity of the maximum angular distortion, and frequently occurred elsewhere in the building. The authors could not provide a satisfactory explanation for this phenomenon.

While characteristics and typical spans of buildings vary from those of bridges, the threshold values for $A, \Delta$, and $\delta$ obtained in the referenced studies are not inconsistent with data obtained for bridges, which are discussed hereafter. The value of the above-cited studies is in the fact that they summarize experimental data for structures which were not otherwise designed to accommodate differential settlements.

Data are also available from mine subsidence studies [Yokel et al., 1982], however in the latter case the recorded damage is in part attributable to horizontal ground strains, which are not likely to occur as a result of isolated footing loads.

Until recent studies by FHWA [Moulton et al., 1985, Moulton, 1986] were completed, only a limited amount of data was available on the tolerance of bridges to foundation displacements. The FHWA studies cover the performance of 314 bridges in the U.S. and Canada. Of these 314 bridges, 104 are founded on fine grained soils and 15 on fine grained soils underlain by sands. It is reasonable to assume that in a substantial portion of the bridges which were underlain by finegrained soils most of the settlement occurred after the superstructure was in place.

Forty percent (125) of the bridges were founded entirely on spread footings and 30 (95) were supported entirely by piles. The settlements experienced by the 
bridges supported by piles were comparable to those founded on spread footings. While the bridges surveyed are not a representative sample of the entire bridge population (the bridges selected experienced foundation displacements and thus were not selected at random), they do represent a fairly large sample from which damage thresholds for bridges, which were not specifically designed to accomodate differential settlements, can be determined.

The data, while describing the type of damage encountered, place displacements ("movements") into two categories: "tolerable " and "not tolerable". For not tolerable movements the definition of Transportation Research Board (TRB) Committee $\mathrm{A} 2 \mathrm{KO} 3$ was adopted:

Movement is not tolerable if damage requires costly maintenance and/or repairs and a more expensive construction to avoid this would have been preferable.

Intolerable displacements covered by the above definition fit failure categories III and IV as defined in the performance criteria (Section 4.1). Also implicit in the definition is the cost-benefit criterion which was recommended in Section 4.1 as a test for acceptable performance for these failure categories.

The data do not explicitly define failures falling under categories I, II or III, even though some of the information can be used to identify some such failures.

The following findings were derived from the data. Displacements are defined as "tolerable" when they were judged to be tolerable in 908 or more of the reported cases:

1. Maximum Tolerable Angular Distortion:

0.004 for continuous bridges

0.005 for simple spans.

Reinforced concrete bridges had a higher tolerance threshold than steel bridges. The small difference between simple spans and continuous bridges 
seems to indicate that for these small angular distortions much of the observed damage was probably not caused by yielding of primary structural members.

2. Maximum Tolerable Total Displacements:

vertical displacement only ......... in. (50 mm) horizontal displacement only ........ in. (25 mm)

horizontal and vertical (sensitivity increases when both are combined) vertical component $\ldots \ldots \ldots \ldots \ldots \ldots 1$ in. (25 mm) horizontal component ............ in. (25 mm)

The data also address the problem of riding comfort. While no specific threshold was established, it was noted by Moulton et al. that displacements associated with riding comfort problems are greater than those associated with intolerable damage. Thus, no threshold needs to be established under the performance criteria (riding comfort will be taken care of by keeping displacements below the damage threshold or by jacking if necessary).

Although the number of data points is too small to allow conclusions to be drawn, the data indicate that tolerable displacements for some simple span bridges were much larger than 2 in. (50 mm) [up to 8 in. (200 mm)]. Differences between two-span and multi-span continuous bridges are not identified in the study.

It is important to note that the tolerable displacements derived from the bridge study are not inconsistent with those derived for buildings. The maximum tolerable vertical displacements were found to be the same for bridges and buildings ( 2 inches). The maximum tolerable angular distortion for bridges $(1 / 250)$ was found to be somewhat greater than that for buildings $(1 / 300)$. However, the bridge data were not corrected for possible rigid-body tilt, resulting in a potential increase in calculated angular distortions. 
When these data are used as a basis for design criteria, it is important to note that, for bridges founded on granular soils, much of the settlement will occur before the deck is in place and thus will not adversely affect the superstructure. This is not the case in buildings, where much of the settlement occurs after completion of the lowest story. Thus the construction sequence can be taken into consideration when determining tolerable settlements for bridge foundations on granular soils.

Another part of the reports by Moulton et al. deals with analytical studies of differential-settlement effects on bridge deck structures. The study deals with steel as well as concrete structures, although not all the aspects of concrete structures are addressed. Design aids are presented, and procedures for design modifications to accommodate differential settlements are suggested.

Some of the analytical data generated by Moulton et al. can be used to examine the effect of the settlements. This is done hereafter for composite girder bridges which were analyzed for realistic design situations. The data are taken from Moulton et al., 1982, which is an earlier, more detailed version of the work addressed in Moulton, 1986. Typical cross sections are shown in Fig. 5.2. Steel girders of compact sections were used (AASHTO, 1985, Sec. 10.50.1.1.2) and sizes were selected in accordance with span lengths. Girder spacing was not found to be a significant parameter with respect to settlement effects. Settlement-induced moments were calculated using the gross composite section, assuming full composite action between steel and concrete and giving no consideration to concrete cracking in regions of negative moments. This results in estimated settlement-induced moments which are greater than those the structure would actually experience (a very conservative estimate). Stress increases for negative moments were calculated for the flanges of the steel girders (not the reinforcing bars in the deck). For the 3-span sections the conservative assumption was made that for maximum negative moments both end supports settled by the amount indicated for differential settlement.

Figures 5.3 and 5.4 show data for computed elastic stress increases caused by added negative moments at interior supports, assuming that the adjacent supports settled. The data were taken from Table 32 in Moulton et al., 1982. The solid 

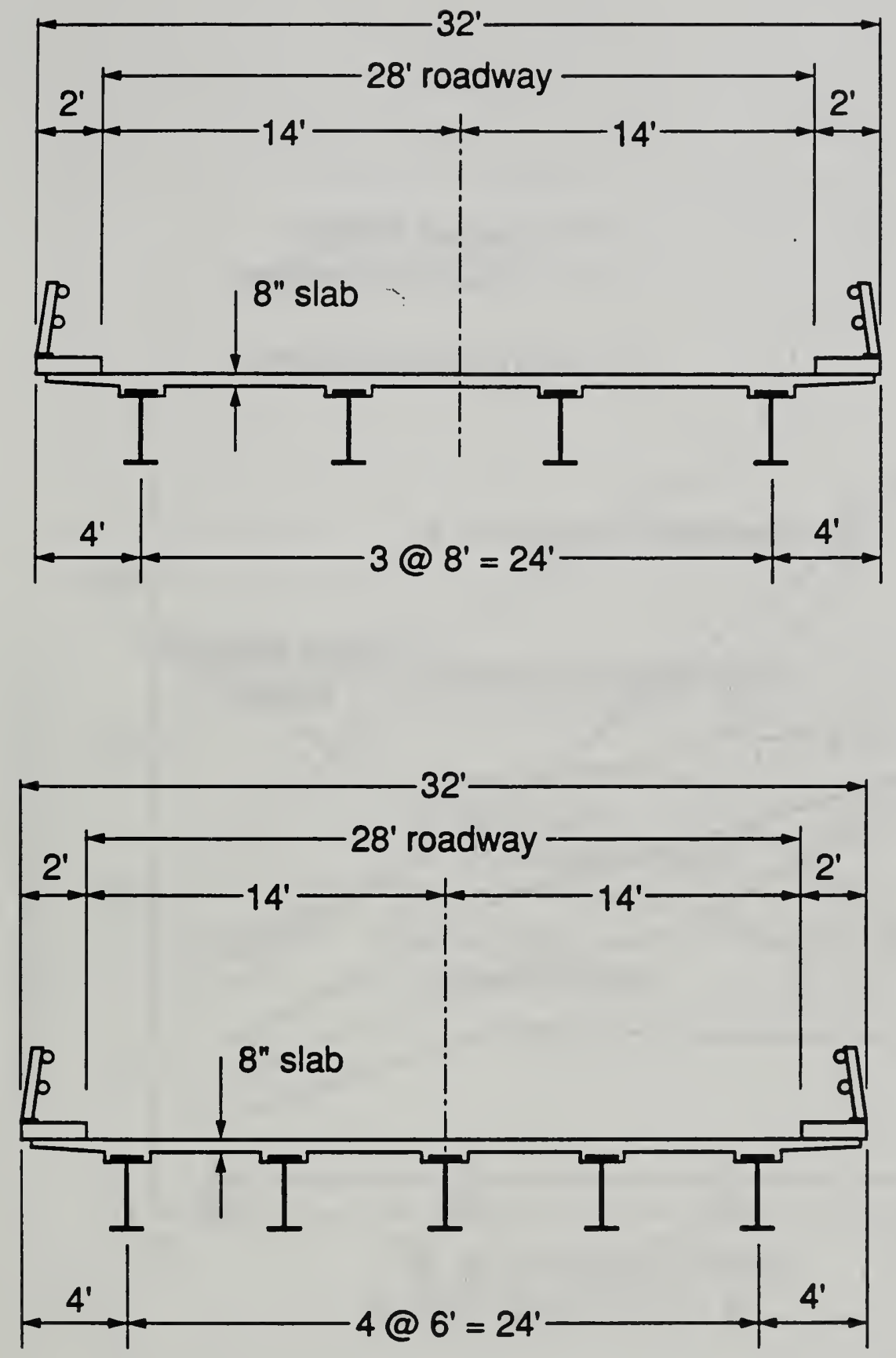

Figure 5.2: Typical Composite Girder Cross Sections Used in the Study of Differential-Settlement Effects. 


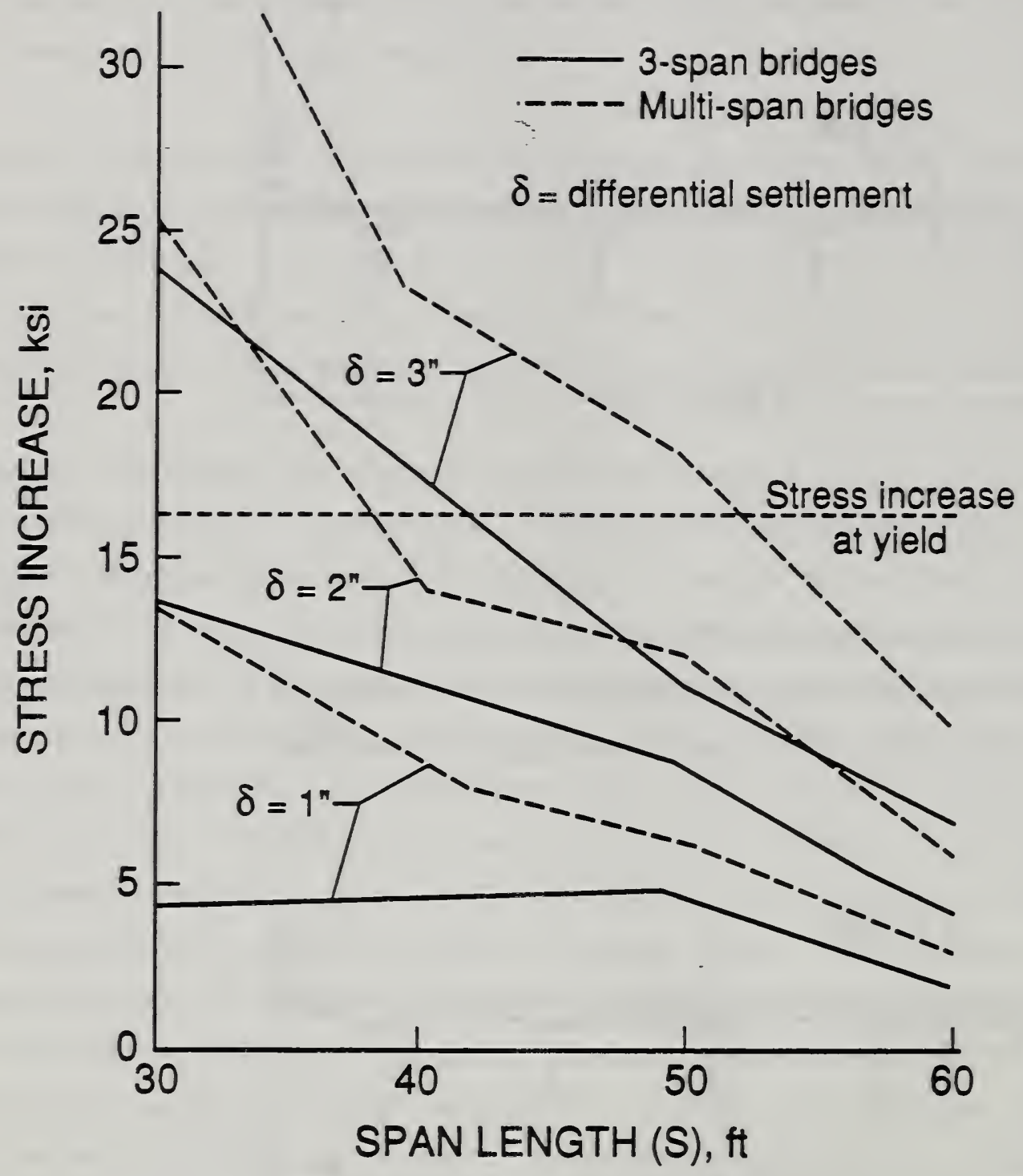

Figure 5.3: Stress Increases in Steel Girders of Typical Composite Girder Bridges Caused by Settlement Induced Negative Moments. 


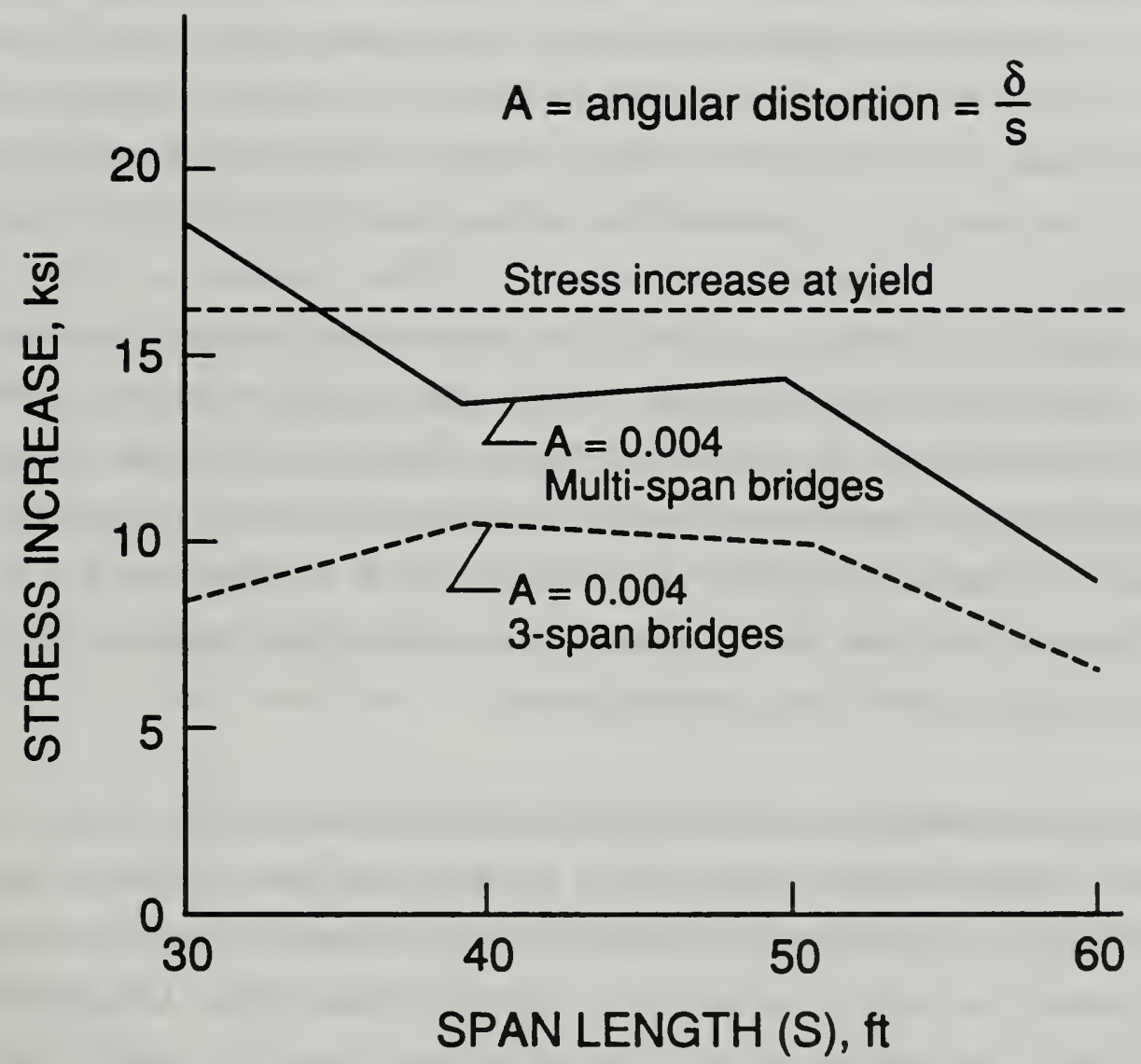

Figure 5.4: Stress Increases in Steel Girders of Typical Composite Girder Bridges Caused by Angular Distortions of 0.004 Radians. 
curves in figure 5.3 show stress increases in ksi ( $1 \mathrm{ksi}=6.9 \mathrm{MPa}$ ), calculated in accordance with the previously-described procedure for 3-span bridges. The dashed curves are for multi-span bridges. The curves are shown for differential settlements of 1,2 , and 3 inches $(25,50$, and $75 \mathrm{~mm}$ ). The dotted horizontal line in the figure shows a stress of $16.2 \mathrm{ksi}$ (112 $\mathrm{MPa}$ ), which is the stress increase under working load at which girders designed for the maximum allowable stress are designed to yield.

Note that the induced stress increases as the span decreases. Note also that neither 3-span nor multi-span continuous bridges would yield as a result of the maximum settlement-induced negative moment combined with the maximum working load if they are subjected to a differential settlement of 1 inch (25 mm). The same is true for a differential settlement of 1.2 inches ( $30 \mathrm{~mm}$ ), which was identified by Grant et al. $(1972,1974)$ as the threshold for differentialsettlement induced damage. The two dash-dotted lines in figure 5.4 show the estimated effect of an angular distortion of 0.004 radians on three-span and multi-span bridges. It can be seen that all three-span bridges, and multi-span bridges with spans over $35 \mathrm{ft}(11 \mathrm{~m})$ would not yield under the settlementinduced negative moments. In the actual calculations by Moulton et al., 1982, all $30-f t$. span bridges were found to be stressed below the allowable serviceload stress and therefore no yield would occur for $A \leq 0.004$ and $\delta \leq 1.2$ inches (in the short-span sections the girders were oversized because of practical design considerations, and thus understressed).

The above-referenced analysis used a very simplified model and chose the option of no composite action between the steel girders and the concrete deck in the negative-moment region. If the longitudinal reinforcement is continuous over the pier and appropriate shear connectors are provided, the longitudinal slab reinforcement would be subjected to a larger strain than the upper flange of the supporting girder, but its composite action with the girder would increase the section modulus and thereby lower the tensile stresses. It should also be noted that the minimum yield strength of the concrete reinforcement is $60 \mathrm{ksi}$ ( 414 $\mathrm{MPa}$ ), while a $36-\mathrm{ksi}(248-\mathrm{MPa})$ steel beam strength is assumed in the figure. Another factor that needs to be considered is that in the referenced report the negative moments were calculated on the basis of gross-section stiffness. Had 
actual (cracked-section) stiffness been used in the negative moment region, the calculated settlement-induced moments would have been much smaller. When all these factors are considered it is apparent that the maximum negative moments induced by a differential settlement of 1.2 inches (30 mm) or less or an angular distortion of 0.004 radians or less would not cause yield of the deck reinforcement when the bridge is subjected to the design working loads. This confirms that no excessive deck cracking would occur below the observed damage thresholds for composite deck type steel bridges.

The previous discussion concentrated on negative-moment effects. Yield in the bottom flange of steel girders caused by positive moments, resulting in a permanent set associated with a moderate angular rotation would not cause observable deck cracking or otherwise unacceptable damage. Neither would the ultimate strength of the composite girder be affected as long as conditions discussed later in this section are satisfied.

The study presented by Moulton et al., 1985, also deals with other bridge types. As far as other, larger span steel bridges are concerned, the effects of settlements below the damage threshold values would be less severe than that shown in Fig. 5.3, and become negligible for spans of in excess of $100 \mathrm{ft}(30 \mathrm{~m})$ length. In the case of concrete bridges, the effects are more complex and many variables were not explored in the study. This case will be addressed in more detail in the next section.

Moulton et al., 1982, 1985, and Moulton, 1986 also present charts which could be used to modify bridge design to accomodate differential settlement. They recommend to accomodate settlements either by modifying allowable stresses or by considering the settlement effects as a design load. 


\subsection{Design Limit States and Criteria for Shallow Bridge Foundations}

\subsubsection{Types of Limit States}

Two types of limit states must be avoided:

1. Serviceability limit states, which include unacceptable damage or disfunction, such as excessive cracking of concrete decks, jaming of joints, or displacements which adversely affect riding comfort and drainage.

2. Ultimate (failure) limit states, which include fatigue failures and failures under ultimate load.

Allowable settlements must either be based on predetermined damage thresholds or on rational consideration of specific limit states. It is important to note that all bridges designed by present standards experience displacements which they were not designed to accomodate. Therefore the rational damage criteria need only be applied if the anticipated foundation displacements approach or exceed empirically or rationally determined damage thresholds.

\subsubsection{Serviceability Limit States:}

1. Empirical Damage Thresholds

The empirically established damage thresholds were previously discussed. These thresholds are backed by a considerable amount of field data, and were shown to be theoretically justifiable for composite-deck bridges, which are the most common in the span range of concern.

\section{Empirical Functional Thresholds}

It was shown that the damage thresholds are lower than the riding comfort threshold. Thus criteria for riding comfort are not necessary. The thresholds for horizontal displacements reflect tolerances in joints and bearings inherent 
in present design practice and they are backed by a considerable amount of field data.

\section{Rational Damage Criteria}

\section{Excessive Deck Cracking}

Excessive deck cracking is only a concern when the differential settlement results in an increase in the negative moment over a pier. This added negative moment would result in significant added tensile forces in the longitudinal deck reinforcement if and only if there is composite action between the girder and the tensile reinforcement of the deck. If there is no composite action the induced tensile forces would be negligible. For composite action to occur in the case of a composite girder the longitudinal deck reinforcement must be continuous over the pier and adequate shear connectors between the girder and the deck must be provided. If composite action is assumed for calculating additional tensile forces in the deck reinforcement over the piers, it also should be assumed when the section modulus of the composite girder is calculated. Increase in positive moments due to differential settlements would result in compressive forces in the deck which would not cause damage.

The following criteria are proposed to ensure that excessive cracking will not occur:

(1) The longitudinal deck reinforcement shall not yield under the sum of the negative moment caused by the applicable portion of the differential settlement at service loads and the negative moment caused by the overload, where the overload is $1 \mathrm{D}+1.67 \mathrm{~L}$. The applicable portion of the differential settlement at service loads is 758 of the total settlement attributable to a load of $1 \mathrm{~L}+1 \mathrm{D}_{\mathrm{p}}$ where $\mathrm{D}_{\mathrm{p}}$ is the dead weight applied after the bond between the longitudinal deck reinforcement and the surrounding concrete achieved 258 of its 28 -day strength.

(2) The reinforcement spacing shall be in compliance with Section 8.16 .8 .4 of AASHTO 1983, where $f_{s}$ in Equation 8-61 shall be the sum of the service- 
load stress and the stress attributable to the applicable portion of the differential settlement at service loads.

The criterion in (1) is in compliance with the intent of proposed provisions for alternate load factor design procedures [Grubb, 1987, AASHTO, 1985 (1)]. Settlements are calculated for the full service load, but not for the overload which is not likely to act long enough to affect foundation settlements. The provision in (2) would ensure that the crack width in the cracked portion of the concrete deck would not exceed tolerable limits. The AASHTO provision provides adequate protection even to concrete members subjected to tension, such as a composite-girder bridge deck in the negative moment region [ACI Committee 224 , 1986, Eq. 3.8].

Note that for the range of live to total load ratios between 60 and 658 for 30$50 \mathrm{ft}$ (10-16 m) long spans ultimate strength considerations, rather than AASHTO Equation 8-61 govern the level of service-load reinforcement stress [refer to Halvorsen, 1987, and U.S.Steel, 1956, fig.9]. Thus a substantial stress increase from differential settlements can be accommodated before concrete cracking control becomes critical.

It should also be noted that, particularly in the case of certain types of concrete bridges, $D_{p}$ is a very small portion of the total dead weight.

\section{Functional Criteria}

No rational criteria are available for riding discomfort, however Moulton et al., 1985, and Moulton, 1986, provide evidence that damage thresholds, rather than riding comfort thresholds will govern the design. Potential problems associated with jamming of bearings or joints or drainage must be evaluated in each individual case for conditionally allowable settlements. 


\subsubsection{Ultimate Limit States}

1. Empirical Failure Thresholds

Some empirical failure thresholds can be derived from Moulton et al., 1986 for settlement-induced structural failures. However, settlements which would induce major structural failures are much larger than those associated with deck cracking and thus do not govern the design of shallow foundations. It is also obvious that bearing-capacity failures of shallow foundations would lead to structural failures. The problem that needs to be addressed in terms of allowable settlements is whether a differential settlement of a given magnitude will reduce the strength of the structure either in terms of required fatigue strength or in terms of required ultimate strength. Because of the low probability of occurrence of either fatigue or ultimate load failures, the available data cannot answer this problem and empirical thresholds for these cases are therefore not available.

2. Rational Strength Criteria

\section{Fatigue Strength}

\section{Steel Girders}

In terms of the present AASHTO specifications the allowable fatigue stress range is solely dependent on the number of stress cycles and is independent of the prevailing stress level (refer to Chapter 10.3.1 of the AASHTO Specifications). Thus in terms of current AASHTO provisions additional stresses attributable to differential settlements do not affect the allowable fatigue stress range and therefore no criterion is required.

Available data, however, indicate that the fatigue strength range for a given number of stress cycles does depend on the magnitude as well as the range of the applied stresses (i.e. refer to Goodman diagram, figure 2.11.4 in Salmon, 1980). It is assumed that the stress range allowed in AASHTO is based on the premise that the maximum allowable working stress is utilized in the design of the 
bridges. This is, however, not always the case for bridges in the critical 30 to $50 \mathrm{ft}(10$ to $17 \mathrm{~m})$ length range. Neither does the design load act on the bridge very often, if ever [Moulton et al., 1982]. Thus the effect of differential settlements on fatigue strength can be safely disregarded.

\section{Concrete Reinforcing}

The following criterion is proposed:

The fatigue stress limit stipulated in Section 8.16.8.3 of the AASHTO Specifications shall not be exceeded. The term " $f_{m i n}$ in Eq. (8-60) of the AASHTO Specifications shall be the minimum stress + the stress attributable to the applicable portion of the differential foundation settlement at service load.

It should be noted that for the live to total load ratios for bridge spans in the critical length range from 30 to $50 \mathrm{ft}(10-17 \mathrm{~m})$ the allowable fatigue stress range does not govern the design [Halvorsen, 1987, Fig. 9].

\section{Ultimate Strength}

The ultimate strength of bridges is of concern because it is a measure of the failure probability which should not be increased as a result of anticipated differential settlements. For steel bridges, as well as concrete bridges whose ultimate strength is governed by the yield strength of the reinforcement, the ultimate strength is not affected by differential foundation settlements, if the rotational capacity at the plastic hinges which form at the locations of maximum moment is adequate to accomodate the rotation associated with differential settlements in addition to any rotation that may be required for the moment redistribution assumed in the design. If this latter condition is not satisfied, differential settlement effects must be considered as additional design loads and allowed for in the design. Whether or not differential foundation settlements will affect the ultimate strength of a bridge will thus depend on the bridge type, as well as the magnitude of the anticipated differential settlements. This problem is subsequently discussed. 


\section{Composite Steel Girders}

The most common bridge type in the critical span range are composite steel girders. Recently developed draft guide specifications [Grubb, 1987, AASHTO, 1985 (1)] allow a transfer of up to 108 of the negative moment when ultimate load capacity is calculated, which results in a positive-moment increase of approximately 48. Data on moment rotation capacity indicate that in negative bending, composite steel beams which meet the AASHTO criteria for compactness have a rotation capacity on the order of 0.06 radians [Grubb, 1987, Fig.7], more than an order of magnitude larger than the rotations associated with the maximum allowable differential settlements recommended. Thus, negative moments associated with differential settlements will not reduce the ultimate load capacity of composite girders.

Differential foundation settlements could also reduce negative moments and thereby increase positive moments. In most instances this would not change the ultimate moment capacity of the bridge, because the negative moment hinge will form first, and the decrease in negative moments would at most cause both hinges to form simultaneously, and thus would have a beneficial effect on strength. However in the rare cases where the differential settlement effect would cause the positive moment hinge to form first, some positive moment rotation capacity would be required. Unfortunately there are no data on the positive moment rotation capacity, and it is presently assumed that there is no rotation capacity [Grubb, 1987]. Even though this latter assumption is considered unreasonable (it probably has been arbitrarily made because positive moment rotation capacity would not contribute to the ultimate strength of the bridge), the assumption of no rotation capacity imposes a limit on the negative-moment reduction (and positive-moment increase) that can be allowed before differential-settlement effects must be considered as design loads. The following criterion is proposed:

The positive moment due to the sum of the positive moment attributable to the factored dead and live loads and the most critical positive moment caused by the applicable portion of the differential settlement at ultimate load shall satisfy the following inequality: 


$$
M_{p+} / M_{p-} \geq M_{e+} \cdot / M_{e-}
$$

where: $\quad \mathrm{M}_{\mathrm{p}^{+}}=$positive plastic moment capacity

$\mathrm{M}_{\mathrm{p}-}$ = negative plastic moment capacity

$\mathrm{M}_{\mathbf{e}}{ }^{\prime}=$ elastic moments due to service load + applicable portion of differential settlement at ultimate load.

The applicable portion of the differential settlement at ultimate load is defined as the applicable portion of the differential settlement at service load $+1 / 2$ the total settlement attributable to the difference between the service load and the ultimate load.

This latter definition is based on the following assumptions:

(1) It is conservatively assumed that the ultimate load will act long enough and in such a manner as to cause an instantaneous foundation settlement corresponding to the ultimate load, but will not act long enough to cause any creep settlement.

(2) Estimated settlements are the sum of an instantaneous and a creep settlement (a reasonable allowance for creep is implicit in the estimates).

(3) The portion of the settlement attributable to creep is estimated by a method for sandy soils, recommended by Schmertmann, 1970, which in turn is based on data developed by others [Nonveiler, 1963, Brinch-Hansen, 1966] as follows:

$$
D_{(t)}=D_{(0)}[1+0.2 \log (t / 0.1)] \quad \ldots(4.2)
$$

where: $\quad D_{(t)}=$ settlement at time $t$

$$
D_{(0)}=\text { instantaneous settlement }
$$$$
t \quad=\text { time in years }
$$

If the predicted settlements occur at the end of a 20-year period, the instantaneous total settlements are approximately 688 of the predicted 
settlements and the instantaneous differential settlements are 508 of the predicted total settlements. (Note that Eq 4.2 is not generally accepted and is considered to predict creep settlements very conservatively [Gifford, 1987]. However, further unpublished work on Gifford's data indicates that most observed bridges did experience a creep settlement. At the present time no other equation for creep settlements of bridge foundations in granular soils is available.)

\section{Plate Girders}

While LRFD procedures have been proposed for the design of plate girders [Zahn, 1987], these procedures do not include moment redistribution, and it would not be conservative to assume that substantial inelastic deformations can be accommodated. Fortunately plate girders are associated with larger spans where differential settlement effects tend to be negligible. Thus in ultimatestrength design it is proposed to include the applicable portion of differential settlement effects at ultimate load. The following criterion is proposed:

Moments and shear induced by the applicable portion of the differential settlements at ultimate load shall be considered in the design.

\section{Steel Trusses}

LRFD procedures for steel trusses have been proposed by AASHTO, 1985 [2]. Large spans are involved and differential settlement effects are negligible. Furthermore, differential settlement effects would not reduce the ultimate-load capacity of steel trusses. Thus no criteria are needed.

\section{Concrete Bridges}

Concrete beams have rotational capacity if they are underreinforced and failure is initiated in the steel reinforcement [Cohen, 1965, Mattock, 1959]. Rotational capacity is much enhanced if there is tensile, as well as compressive reinforcement. AASHTO specifications do not allow moment redistribution in 
concrete bridges. However, ACI 318-83 in Chapter 8.4 permits transfer of between 10 and $20 \%$ of the moment if the reinforcement ratio does not exceed $50 \%$ of that producing balanced strain conditions. It is assumed, that differentialsettlement induced moments of a magnitude not exceeding that stipulated in ACI 318 can be accommodated by moment rotation without reducing the ultimate strength of the bridge. Data given in the commentary to Section 8.4 of ACI 318 indicate that the moment transfer allowed is conservative. Thus the following criterion is proposed:

Moments due to the applicable portion of the anticipated differential settlements at ultimate load, not exceeding those stipulated in Section 8.4 of ACI $318-83$ shall not reduce the ultimate strength of the bridge. Differential-settlement effects in excess of those previously stipulated shall be considered in the design and added to the moments and shear attributable to factored live and dead loads.

\subsection{Allowable Displacements}

\subsubsection{Definitions}

Unconditionally Allowable Displacements are displacements which are permitted without any special design consideration.

Conditionally Allowable Displacements are displacements which are permitted if the bridge is designed to accomodate the estimated differential settlements or if compliance with the conditions discussed in this section and summarized in Section 6.3.2 is demonstrated.

The Applicable Portion of a Settlement at Service Load is the settlement attributable to a load of $1 \mathrm{~L}+1 \mathrm{D}_{\mathrm{p}}$ where $\mathrm{L}$ is the service live load and $\mathrm{D}_{\mathrm{p}}$ is the dead weight applied after the bond between the longitudinal deck reinforcement and the surrounding concrete achieved 258 of its 28-day strength. 
The Applicable Portion of a Differential Settlement at Ultimate Load is the applicable portion of the differential settlement at service load $+1 / 2$ the total settlement attributable to the difference between the service load and the ultimate load.

\subsubsection{Displacement Components}

Differential Settlement shall be assumed 758 of the maximum total settlement or the range between the maximum and minimum calculated settlement, whichever is more.

Angular Distortion between bridge supports at opposite ends of a span shall be the differential settlement divided by the span length.

Angular Distortion between Closely-Spaced Foundation Elements or Rigid-Body Rotation of Any One Foundation Elenent shall be taken as $1 / 600$ th the maximum total settlement in inches, measured in radians.

Rigid-Body Rotation of a Foundation Exerting Non-Uniforn Pressure on the Supporting Soil shall be taken as the square root of the sum of the squares of the calculated rotation and $1 / 600$ the maximum total settlement in radians.

\subsubsection{Calculation of Displacements}

The displacement limits in 5.4.4 apply to settlements calculated for unfactored loads. If settlements are calculated deterministically they should represent an estimated upper bound rather than an estimated mean settlement. Should a more sophisticated approach be used, where the mean and standard deviation of the settlement are estimated, the design settlement should not be less than the predicted mean settlement +1.3 standard deviations. Guidance can be derived from Gifford, 1988, page 65. Footings proportioned in accordance with Peck et al., 1974, Section 19 are unlikely to exceed the unconditionally allowable maximum settlement specified in 5.4 .4 . 


\subsubsection{Displacements Limits}

\section{Unconditional Allowable Maximum Displacements}

A total settlement of 1 inch $(25 \mathrm{~mm})$ or $1 / 600$ th the span length, whichever is less.

A horizontal displacement of $3 / 8$ inches $(10 \mathrm{~mm})$.

\section{Conditionally Allowable Maximum Displacements}

A total settlement of 2 inches $(50 \mathrm{~mm})$ or $1 / 300$ th the span length, whichever is less; a horizontal displacement of $3 / 4$ inches (20 mm).

\section{SUMMARY OF PROPOSED DESIGN CRITERIA}

\subsection{Design Loads:}

\subsubsection{Service Load Combinations}

The most critical load combination applicable to foundation design specified in AASHTO 1983, as subsequently amended, Table 3.22.1. A should be applied. Group I loading is relevant for all areas, and Group VI loading must be satisfied wherever applicable in accordance with the seismic risk map in Figure 3.21.1.E.

\subsubsection{LRFD Design}

The most critical load combination applicable to foundation design specified by AASHTO 1983, as subsequently amended, Table 3.22.1.A should be applied. The factored loads would decrease significantly when the dead load is large compared to the live load. It is therefore recommended that the design gravity load not be smaller than 1.5(Dead + Live), which is the factored load for a 200-ft (60 $\mathrm{m})$ long span. This latter recommendation is in agreement with the AASHTO "Guide Specification for Strength Design for Truss Bridges", 1985. As in the case of 
service load combinations, Group I and VI loadings are applicable in most instances.

When the design of the superstructure is to be modified because anticipated differential settlements are deemed to affect the load capacity of bridges, applicable settlement effects corresponding to the level of the factored loads used in the design of the superstructure should be considered.

\subsection{Design Criteria}

\subsubsection{Design Limit States:}

1. Bearing capacity failure

2. Rotational sliding

3. Sliding at the base of the footing

4. Settlements which cause failure or impair the load capacity of the structure

5. Settlements which cause structural distress or functional failure.

\subsubsection{Failure Categories}

I: Catastrophic failure - a failure associated with loss of life and major loss of property, or the protracted disruption of traffic in a major artery. An example of a catastrophic failure would be a foundation failure which would collapse a bridge span in a major artery.

II: Major structural failure - a foundation failure which renders all or a major part of the bridge structure or its foundation unserviceable until a major structural component is replaced. An example would be a flexural or shear failure in a bridge girder as a result of excessive settlements.

111: Structural distress - A failure which requires repair work or which is esthetically unacceptable or impairs durability, but does not render the bridge unserviceable. An example would be an unacceptable level of cracking in the deck. 
IV : Functional failure - a failure which temporarily or permanently causes the bridge or its approaches to fulfill their function improperly (for instance drainage or riding comfort problems caused by settlements).

\subsubsection{Safety Margins}

(1) Working Load Design:

The safety factor against Limit states 1, 2 and 3 should be not less than 3.6 for Category I failures and 3 for Category II failures. Limit State 4, if applicable, must be evaluated by the LRFD method. The safety factor of 1 is suggested for Limit State 5 with respect to estimated upper bound displacements.

\section{(2) LRFD Design:}

For limit states 1,2 , and 3 :

The inequality that must be satisfied in LRFD design is:

$\Phi R \geq \operatorname{IF}\left(\gamma_{D} D+\gamma_{L} L\right)$

where: $\quad \gamma_{D}$ and $\gamma_{L}=$ the load factors for dead and live load

$\Phi=$ a capacity reduction factor

IF $=$ an importance factor

$$
\begin{aligned}
& \text { IF }=0.45 \cdot I^{0.2} \text { for Category II failures } \\
& \text { IF }=0.54 \cdot I^{0.2} \text { for Category I failures } \quad \ldots(4.8)
\end{aligned}
$$

There is as yet no professional consensus on how to determine the capacity reduction factor. One possible approach is discussed in Section 4.3.

For limit state 4: use factored loads as noted, and $\Phi=1$.

For limit state 5: use a load factor of 1 for live loads and unfactored dead loads, and either upper bound settlement estimates if settlements are deterministically determined, or $\Phi=1+1.3 \mathrm{v}$, where $\mathrm{v}$ is the coefficient of variation for the estimated settlement if the mean and variance of anticipated settlements is estimated. 
(4) Probabilistic Design:

This approach can only be used when soil exploration data of sufficient quantity and quality are provided. An adequate justification must be provided for the safety margins used. Target safety indices of not less than 3.5 and 2.5 are suggested for Category I and II failures, respectively. A safety index of not less than 1.3 (a 108 exclusion limit) is suggested for limit state 5 , unless a different safety index can be justified by a cost-benefit analysis.

If a probabilistic approach is used, the variability of the soil resistance must be fully documented by the engineer on the basis of soil exploration and laboratory test data.

\subsection{Allowable displacements:}

\subsubsection{Unconditionally Allowable Maximum Displacements}

A total settlement of 1 inch $(25 \mathrm{~mm}$ ) or $1 / 600$ th the span length, whichever is less.

A horizontal displacement of $3 / 8$ inches $(10 \mathrm{~mm})$.

\subsubsection{Conditionally Allowable Maximum Displacements}

A total settlement of 2 inches $(50 \mathrm{~mm}$ ) or $1 / 300$ th the span length, whichever is less.

A horizontal displacement of $3 / 4$ inches $(20 \mathrm{~mm}$ ).

\section{Conditions for conditionally allowable Displacements}

For any displacement exceeding the unconditionally allowable displacements the following conditions must be met. Displacements exceeding the conditionally allowable displacements are prohibited. 


\section{All Bridges}

1. Potential adverse effects of abutment settlements shall be mitigated by an appropriate approach slab.

2. Adequate clearance and displacement tolerances in bearings and joints shall be provided to accomodate twice the anticipated maximum horizontal displacements.

3. The drainage system shall be designed to remain functional after the maximum anticipated displacements occurred.

4. The bridge shall be designed to accomodate the applicable portion of anticipated differential settlements, or alternately the following conditions must be satisfied for continuous-span bridges:

a. The longitudinal deck reinforcement shall not yield when subjected to the sum of the negative moment caused by the applicable portion of the differential settlement at service load and the negative moment caused by the overload, where the overload is $1 \mathrm{D}+1.67 \mathrm{~L}$.

b. The reinforcement spacing shall be in compliance with Section 8.16.8.4 of the AASHTO Specifications for Bridges [6] where $f_{s}$ in AASHTO Equation 8-61 shall be the sum of the service-load stress and the stress attributable to the applicable portion of the differential settlement at service load.

\section{c. Concrete Reinforcing}

The fatigue stress limit stipulated in Section 8.16.8.3 of the AASHTO Specifications shall not be exceeded. The term" $f_{m i n}$ " in AASHTO Eq. $(8-60)$ shall be the minimum stress plus the stress attributable to the applicable portion of the differential foundation settlement at service load. 
d. Composite Steel Girders (compact Sections)

The positive moment due to the sum of the positive moment attributable to the factored dead and live loads and the most critical positive moment caused by the applicable portion of the differential settlement at ultimate load shall satisfy the following inequality:

$$
M_{p+} / M_{p-} \geq M_{e+}{ }^{\prime} / M_{e-}, \quad \ldots \ldots \ldots \ldots \text { Eq (4.1) }
$$

where: $\quad \mathrm{M}_{\mathrm{p}_{+}}=$positive plastic moment

$\mathrm{M}_{\mathrm{p}_{-}}$= negative plastic moment

$\mathrm{M}_{\mathbf{e}^{\prime}}$ = elastic moments due to factored load + the applicable portion of differential settlement.

e. Plate Girders and Non Compact Steel Girders

Moments and shear induced by differential foundation settlements shall be considered in the design as follows: In the working load method of design the most critical moments and shears attributable to the applicable portion of the differential foundation settlement at service load shall be added to the design moments and shears. In the LRFD method the most critical moments and shears attributable to the applicable portion of the differential settlement at ultimate load shall be added to the moments and shears for factored dead and live loads.

\section{f. Concrete Bridges}

Moments due to the applicable portion of the anticipated differential settlements at ultimate load, not exceeding those specified in Section 8.4 of ACI 318-83 shall not reduce the ultimate strength of the bridge. Differential-settlement effects at ultimate load in excess of those previously specified shall be considered in the design and added to the moments and shears attributable to factored live and dead loads. 


\section{REFERENCES}

[1] AASHTO, Guide Specification for Alternate Load Factor Design Procedures for Steel Beam Bridges Using Braced Compact Sections, Draft Copy, August 28, 1985.

[2] AASHTO, Guide Specifications for Strength Design of Truss Bridges, (Load Factor Design), 1985.

[3] AASHTO, Standard Specifications for Highway Bridges, Thirteenth Edition, 1983, Incl. Supplements (1984, 1985, 1986, 1987-8).

[4] ACI 318-83, Building Code Requirements for Reinforced Concrete, November 1983.

[5] ACI Committee 224, Cracking of Concrete Members in Direct Tension, $\underline{J}$. American Concrete Institute, Jan.-Feb. 1986.

[6] AISC, Manual of Steel Construction, Load and Resistance Factor Design, First Edition, January, 1987.

[7] ANSI A58.1-1982, Minimum Design Loads for Buildings and Other Structures, 1982.

[8] Baecher, G.B., Geotechnical Risk analysis: The State of the Art, FHWA Technical Report No. 87/010, 1987.

[9] Baecher, G.B., Geotechnical Risk Analysis: A User's Guide, FHWA Technical Report No. 87/011, March 1987.

[10] Briaud Engineers, Pressuremeter Tests and Settlement Predictions for Five Bridge Abutments on Spread Footings, FHWA Consultant Report, August 1986.

[11] Brinch-Hansen, J., Stress-Strain Relationships for Sand, Danish Geotechnical Institute Bul. No.20, 1966.

[12] Canadian Geotechnical Society, Canadian Foundation Engineering Manual, Montreal, Canada, 1978.

[13] Cohn, M.Z., Rotational Capability in the Limit Design of Reinforced Concrete Continuous Beams, Flexural Mechanics of Reinforced Concrete, (SP12), ACI/ASCE, 1965.

[14] Dimillio, A.F., Performance of Highway Bridge Abutments Supported by Spread Footings on Compacted Fill, FHWA/RD-81/184, October 1982

[15] Dunn, F.P., Reliability Analysis, Overview of Current Practice, Application of Risk Analysis to Offshore Oil and Gas Operations, F.Y. Yokel and E. Simiu Editors, National Bureau of Standards, May, 1985. 
[16] Ellingwood, B. et al., Probability Based Load Criteria: Load Factors and Load Combinations, J. Structural Division. ASCE, Vol. 108, No. ST5, May 1982.

[17] Galambos, T.V., et al.,Probability Based Load Criteria: Assessment of Current Design Practice, J. Structural Division, ASCE, Vol.108, No, ST5, May, 1982 .

[18] Gifford,D.G. et al., Spread Footings for Highway Bridges, Settlement of Footings on Sand, FHWA/RD-86/185, October 1987.

[19] Grubb, M.A., The AASHTO Guide Specification for Alternate Load-Factor Design Procedures for Steel Beam Bridges, Engineering Journal. AISC, 1st Quarter, 1987.

[20] Grant, R. Christian, J.T., and Vanmarcke, E.H., Differential Settlement of Buildings, J. Geotechnical Division, ASCE, Vol.100, GT9, September, 1974.

[21] Grant, R., Christian, J.T., Vanmarcke, R.H., Tolerance of Buildings to Differential Settlement, MIT Soils Publication No.315, Research Report R7279, December 1972 .

[22] Halvorsen, G.T., Code Requirements for Crack Control, prepared for Int. Symp. on Concrete and Concrete Construction, Seattle, WA, November 1987.

[23] Hansell, V.C., Viest, I.M.V. Load Factor Design for Steel Highway Bridges, AISC Engineering Journal, October, 1971.

[24] Mattock, A.H., Redistribution of Design Bending Moments in Re inforced Concrete Continuous Beams, Proc. Inst. of Civil Eng. Vol.13, London, U.K. 1959.

[25] Moulton, L.K., GangaRao, H.V.S., and Halvorsen, G.T., Tolerable Movement Criteria for Highway Bridges, FHWA/RD-85/107, October 1985.

[26] Moulton, L.K. et al., Tolerable Movement Criteria for Highway Bridges, Volume I, Interim Report, FHWA/RD - 81/162, September 1982.

[27] Moulton, L.K., Tolerable Movement Criteria for Highway Bridges, FHWA-TS-85-228, February, 1986.

[28] Nonveiler, E., Settlement of a Grain Silo on Fine Sand, Proc. European Conf. SMFE, Wiesbaden, Germany, 1963.

[29] Peck, R.B., W.E. Hanson, T.H. Thornburn, Foundation Engineering, Second Edition, 1974.

[30] Salmon, C.G.,Johnson, J.E., Steel Structures, 2nd Edition, Harper \& Row, 1980 .

[31] Schmertmann, H.J., Static Cone to Compute Static Settlement over Sand, J. Soil Mechanics \& Foundation Division. ASCE, Vol.96 No. SM3, May 1970. 
[32] Skempton, A.W. and MacDonald, D.H., Allowable Settlement of Buildings, Proceedings. Institution of Civil Engineers, Part III, Vol.5, London, U.K., December 1956.

[33] Snyder, E.R., and Moses, F. Load Factor Design for Substructures and Retaining Walls, Report No. OHIO-DOT-04-78, Case Western Reserve University, Cleveland, OH, November, 1978.

[34] U.S Steel Corporation, Highway Structures Design Handbook, Vol.2, Pittsburgh, PA, 1980.

[35] Whitman, R.V., Evaluating Calculated Risk in Geotechnical Engineering, J. Geotechnical Engineering, ASCE, Vol 110 no.2, February 1984.

[36] Yokel, F.Y., Salomone, L.A., and Gray, R.E., Housing Construction in Areas of Mine Subsidence, J. Geotechnical Engineering. ASCE, Vol 108, GT9, September 1982.

[37] Zahn, C.J., Plate Girder Design Using LRFD, Engineering Journal, AISC, Vol.24, No.1, 1987. 


\begin{tabular}{|c|c|c|}
\hline \multirow{3}{*}{$\begin{array}{l}\text { NIST-114A } \\
\text { (REV. 3-89) }\end{array}$} & \multirow{3}{*}{$\begin{array}{l}\text { U.S. DEPARTMENT OF COMMERCE } \\
\text { NATIONAL INSTITUTE OF STANDARDS AND TECHNOLOGY } \\
\text { BIBLIOGRAPHIC DATA SHEET }\end{array}$} & $\begin{array}{l}\text { 1. PUBLCATION OR REPORT NUMBER } \\
\text { NISTIR } 90-4248\end{array}$ \\
\hline & & PERFORMINO ORQANIZATION REPORT NUMBER \\
\hline & & $\begin{array}{l}\text { 3. PUBUCATION DATE } \\
\text { FEBRUARY } 1990\end{array}$ \\
\hline
\end{tabular}

4. TITLE AND SUBTITLE

PROPOSED DESIGN CRITERIA FOR SHALLOW BRIDGE FOUNDATIONS

5. AUTHOR(S)

Felix Y. Yokel

6. PERFORMINO ORGANIZATION (IF JOINT OR OTHER THAN NIST, SEE INSTRUCTIONS)

U.S. DEPARTMENT OF COMMERCE

NATIONAL INSTITUTE OF STANDARDS AND TECHNOLOGY

GAITHERSBURG, MD 20899

7. CONTRACT/ORANT NUMBER

8. TYPE OF REPORT AND PERIOD COVERED

9. SPONSORING ORGANIZATION NAME AND COMPLETE ADDRESS (STREET, CITY, STATE, ZIP)

Research, Development, and Technology

Turner-Fairbank Highway Research Center

6300 Georgecown Pike

McLean, VA 22101-2296

10. SUPPLEMENTARY NOTES

DOCUMENT DESCRIBES A COMPUTER PROGRAM; SF.185, FIPS SOFTWARE SUMMARY, IS ATTACHED.

11. ABSTRACT (A 2OO-WORD OR LESS FACTUAL SUMMARY OF MOST SIONIFICANT INFORMATION. IF DOCUMENT INCLUDES A SIGNIFICANT BIBUOQRAPHY OR UTERATURE SURVEY, MENTION IT HERE.)

Criteria for the design of spread footings for highway bridges are proposed. The criteria address working load as well as load and resistance factor design (LRFD) procedures. Importance factors to be used in conjunction with the LRFD design format are proposed. The importance factors increase the design loads as the span length increases and also otherwise account for the severity of the consequences of a structural or foundation failure. Further data on LRFD design will be available from studies presently in progress. Available information on tolerances of highway bridges and other structures to foundation displacements are reviewed. On the basis of this information, allowable foundation-displacement limits are proposed. Unconditionally allowable foundation displacements will not affect the strength and serviceability of bridges and therefore do not require structural design modifications. These allowable displacements can be doubled if it either can be demonstrated, using criteria proposed in this report, that the strength and serviceability of the bridge is comparable to that required in accordance with applicable American Association of State Highway and Transportation Officials (AASHTO) specifications, or if the design of the bridge is modified so that the predicted foundation displacements can be accommodated.

12. KEY WORDS (6 TO 12 ENTRIES; ALPHABETICAL ORDER; CAPITALZE ONLY PROPER NAMES; AND SEPARATE KEY WORDS BY SEMICOLONS)

bridges; capacity reduction factors; cohesionless soils;design criteria; design limit states; foundations; foundation settlements; load factors; sands; soil; soil exploration; spread footings

FOR OFFICIAL DISTRIBUTION. DO NOT RELEASE TO NATIONAL TECHNICAL INFORMATION SERVICE (NTIS).

ORDER FROM SUPERINTENDENT OF DOCUMENTS, U.S. GOVERNMENT PRINTINQ OFFICE, WASHINGTON, DC 20402.

$X$ ORDER FROM NATIONAL TECHNICAL INFORMATION SERVICE (NTIS), SPRINGFIELD, VA 22161.

\begin{tabular}{|l|} 
14. NUMBER OF PRINTED PAGES \\
56 \\
\hline 15. PRICE $\mathrm{AO4}$ \\
\end{tabular}




